\title{
Phasic oxygen dynamics underlies fast choline-sensitive biosensor signals in the brain of behaving rodents
}

\author{
Ricardo M. Santos ${ }^{1}$ and Anton Sirota ${ }^{1 *}$
}

${ }^{1}$ Bernstein Center for Computational Neuroscience, Ludwig-Maximilians Universität München, 82152 Planegg-Martinsried, Germany

*Corresponding author:

Anton Sirota

Ludwig-Maximilians Universität München, 82152 Planegg-Martinsried, Germany

Tel. +4989218074805

Fax: +4989218074803

Email address: sirota@biologie.uni-muenchen.de 


\section{Abstract}

1 Fast time-scale modulation of synaptic and cellular physiology by acetylcholine is critical for many

2 cognitive functions, but direct local measurement of neuromodulator dynamics in freely-moving

3 behaving animals is technically challenging. Recent in vivo brain measurements using choline oxidase

4 (ChOx)-based electrochemical biosensors have reported surprising fast cholinergic transients

5 associated with reward-related behavioral events. However, in vivo recordings with conventional

6 ChOx biosensors could be biased by phasic local field potential and $\mathrm{O}_{2}$-evoked enzymatic responses.

7 Here, we have developed a Tetrode-based Amperometric ChOx (TACO) sensor enabling minimally

8 invasive artifact-free simultaneous measurement of cholinergic activity and $\mathrm{O}_{2}$. Strikingly, the TACO

9 sensor revealed highly-correlated $\mathrm{O}_{2}$ and $\mathrm{ChOx}$ transients following spontaneous locomotion and

10 sharp-wave/ripples fluctuations in the hippocampus of behaving rodents. Quantitative analysis of

11 spontaneous activity, in vivo and in vitro exogenous $\mathrm{O}_{2}$ perturbations revealed a directional effect of

$12 \mathrm{O}_{2}$ on ChOx phasic signals. Mathematical modeling of biosensors identified $\mathrm{O}_{2}$-evoked non-steady-

13 state $\mathrm{ChOx}$ kinetics as a mechanism underlying artifactual biosensor phasic transients. This phasic $\mathrm{O}_{2-}$

14 dependence of ChOx-based biosensor measurements confounds phasic cholinergic dynamics readout

15 in vivo, challenging previously proposed $\mathrm{ACh}$ role in reward-related learning. The discovered

16 mechanism and quantitative modeling is generalizable to any oxidase-based biosensor, entailing

17 rigorous controls and new biosensor designs. 


\section{Introduction}

2 Acetylcholine (ACh) is an essential modulator of neuronal circuits engaged in high order cognitive operations. During aroused states, high extracellular ACh sets cortico-hippocampal circuits towards memory encoding by enhancing sensory processing, synaptic plasticity and neuronal network rhythmicity (Hasselmo and McGaughy; Marrosu et al., 1995; Steriade, 2004; Teles-Grilo Ruivo and Mellor, 2013). The latter is particularly relevant in the hippocampus, where ACh plays an important role in the processing of episodic and emotional information via modulation of theta oscillations (Buzsáki, 2002; Gu et al., 2017; Li et al., 2007; Mikulovic et al., 2018; Vandecasteele et al., 2014). Contrarily, low tonic ACh during non-REM sleep permits the occurrence of hippocampal sharpwave/ripple complexes (SWRs), which are critical for memory consolidation (Buzsáki, 2015; Hasselmo and McGaughy, 2004; Norimoto et al., 2012; Vandecasteele et al., 2014). The current theory on the functional role of $\mathrm{ACh}$ in cortical and hippocampal circuits has been mainly derived from brain-state-related correlations of tonic ACh levels with underlying network dynamics, or from strong manipulations of the cholinergic system (Gu et al., 2017; Hasselmo and McGaughy, 2004; Li et al., 2007; Marrosu et al., 1995; Norimoto et al., 2012; Vandecasteele et al., 2014). However, such crude analytic and experimental approaches cannot account for the spontaneous non-stationary interactions between $\mathrm{ACh}$, behavior and neuronal network activity. Recently, fine time-scale measurements of cholinergic activity have provided new insights into these interactions. Fast cholinergic transients in cortical and hippocampal regions have been described in response to sensory sampling, unexpected events, negative reinforcements and reward-related behavior (Eggermann et al., 2014; Hangya et al., 2015; Howe et al., 2017; Lovett-Barron et al., 2014; Parikh et al., 2007; Teles-Grilo Ruivo et al., 2017). The latter have been captured using electrochemical biosensors in response to detection of cues to rewards and reward approach or retrieval in freely-moving rodents (Howe et al., 2017; Parikh et al., 2007; Teles-Grilo Ruivo et al., 2017). The temporally-precise alignment of phasic ACh signals to these events hints for a critical role of ACh on the formation of reward-related memories and on the guiding of learned reward-oriented actions.

The above-mentioned studies highlight the suitability of enzyme-based electrochemical biosensors to capture phasic release of neurotransmitters and neuromodulators(Chatard et al., 2018). Additionally, amperometric measurements pick-up currents generated by the local field potential (LFP) (Viggiano et al., 2012; Zhang et al., 2009), making these sensors ideal for studying the interplay between neuromodulatory tone and neuronal network dynamics. The most successful electrochemical ACh sensing strategy in vivo has relied on the Choline Oxidase (ChOx)-mediated measurement of extracellular choline $(\mathrm{Ch})$, a product of ACh hydrolysis by acetylcholinesterase. The enzyme catalyzes Ch oxidation in the presence of $\mathrm{O}_{2}$, generating $\mathrm{H}_{2} \mathrm{O}_{2}$, which is oxidized on the electrode 
surface (Burmeister et al., 2003; Parikh et al., 2004, 2007; Teles-Grilo Ruivo et al., 2017; Zhang et al., 2010).

However, despite the apparent success of ChOx-biosensors, the factors that can confound their response in vivo at the fast time-scale in freely-moving animals, such as LFP-related artifacts and $\mathrm{O}_{2}$ evoked enzyme transients, have not been thoroughly addressed.

First, the approach that has been conventionally used to cancel LFP-related currents, based on the differential coating of the recording sites with matrices that contain (Ch-sensing sites) or lack $\mathrm{ChOx}$ (sentinel sites), is not optimal. Although differential measurements are essential to clean biosensor signals (Santos et al., 2015; Zhang et al., 2010), $\mathrm{H}_{2} \mathrm{O}_{2}$ diffusion from enzyme-coated to sentinel sites poses important constraints on the sensor design. The inter-site spacing required to avoid diffusional cross-talk leads to uncontrolled differences in the amplitude and phase of LFP across sites, compromising common-mode rejection.

Second, the strategies devised to reduce artifacts that directly generate electrochemical currents (chemical surface modifications or common-mode rejection) and are unrelated to enzymatic response to $\mathrm{Ch}$, do not control for factors influencing ChOx activity. Given that $\mathrm{O}_{2}$ is a co-substrate of the enzyme, it is crucial to control whether physiological $\mathrm{O}_{2}$ variations can contribute to biosensor responses in vivo leading to distortion of true and detection of false positive $\mathrm{Ch}$ signals. Previous studies have only shown that $\mathrm{O}_{2}$ steady-state responses of ChOx-based biosensors in vitro follow apparent Michaelis-Menten saturation kinetics (Baker et al., 2017; Burmeister et al., 2003; Santos et al., 2015). The relatively narrow linear range of $\mathrm{O}_{2}$-dependent biosensor responses, as compared with estimates of average $\mathrm{O}_{2}$ levels in the brain, has motivated the assumption that ChOx-based biosensors are not affected by in vivo $\mathrm{O}_{2}$ dynamics (Baker et al., 2017; Burmeister et al., 2003). That might, however, oversimplify the effect of $\mathrm{O}_{2}$ on enzymatic activity since it widely varies across brain regions and experimental conditions (Lyons et al., 2016; Murr et al., 1994; Nair et al., 1987). Furthermore, previous literature has ignored possible non-steady-state (phasic) biosensor responses to $\mathrm{O}_{2}$, which might arise from local consumption and diffusion of enzyme substrates and reaction products in the sensor coating. These putative transient sensor responses to $\mathrm{O}_{2}$ are particularly relevant as they might temporally overlap with fast cholinergic transients. The full assessment of biosensors' $\mathrm{O}_{2}$ dependence requires the characterization of tonic and phasic $\mathrm{O}_{2}$-evoked responses and the simultaneous in vivo measurement of immobilized ChOx activity (biosensor response) and $\mathrm{O}_{2}$ within the sensor substrate. Yet, when addressed, $\mathrm{O}_{2}$ levels in tissue have been measured using a separate electrode, often of different geometry and/or having a surface material or modification that differs from the Choline-sensing site (Baker et al., 2015; Dixon et al., 2002). This approach is therefore prone to bias from heterogeneous tissue $\mathrm{O}_{2}$ dynamics and differential kinetics of electrode responses to $\mathrm{O}_{2}$.

Here, we have circumvented the above-discussed limitations by designing a novel Tetrode-based Amperometric ChOx (TACO) sensor that provides differential responses to $\mathrm{Ch}$, interferents and LFP 
across four bundled Pt wires. Importantly this multichannel configuration allows the unbiased measurement of the immobilized ChOx activity (COA) and $\mathrm{O}_{2}$ in the same brain spot by using a tetrode site to directly measure the latter. Experiments with TACO sensor in the hippocampus of freely-moving and head-fixed rodents highlight the relevance of our common-mode rejection strategy to provide highly-sensitive contamination-free $\mathrm{COA}$ and $\mathrm{O}_{2}$ signals. We found fast $\mathrm{O}_{2}$ and $\mathrm{COA}$ dynamics following locomotion bouts in active state and hippocampal SWRs during quiescence state. Remarkably, spontaneous $\mathrm{O}_{2}$ and COA transients correlated in amplitude and time regardless of the underlying behavioral or neurophysiological context, a phenomenon we reproduced via causal local or systemic manipulation of $\mathrm{O}_{2}$ dynamics. Our in vivo findings, together with a detailed in vitro characterization and mathematical modeling of $\mathrm{O}_{2}$-evoked biosensor signals reveal a major contribution of spontaneous $\mathrm{O}_{2}$ dynamics to phasic ChOx-based biosensor signals. Importantly, this $\mathrm{O}_{2}$ ChOx-confounding dynamics is associated with behaviorally and physiologically relevant events and warrants important implications for the interpretation of previous studies relying on ChOx sensors as well as for the design of the future enzyme-based sensors.

\section{Results}

\section{Differential plating of TACO sensor discriminates choline from interferents}

TACO sensor is built around $\mathrm{Pt} / \mathrm{Ir}$ wire tetrode, providing a spatial density of recording sites that is ideal for common-mode rejection of LFP-related currents and neurochemical dynamics. At this spatial scale, diffusional crosstalk would preclude the use of sentinel sites by differential coatings, as done in conventional biosensors (Burmeister et al., 2003; Santos et al., 2015). Instead, we created pseudosentinel and Ch-sensing sites by differentially plating the tetrode wires, modifying their electrocatalytic response towards $\mathrm{H}_{2} \mathrm{O}_{2}$. This step was followed by coating the tetrode surface with a common matrix containing ChOx entrapped in chitosan (Santos et al., 2015) (Figure 1A). As for the initial plating steps, all tetrode sites were first mildly plated with gold, which marginally increased the electrode surface area, as inferred from impedances at $1 \mathrm{kHz}(419 \pm 33 \mathrm{k} \Omega, \mathrm{n}=28$ before vs. $370 \pm 16$ $\mathrm{k} \Omega, \mathrm{n}=44$ after gold plating). Despite the slight decrease in impedance, gold-plating significantly decreased the electrocatalysis of $\mathrm{H}_{2} \mathrm{O}_{2}$ reduction/oxidation at the metal surface. In enzyme-coated electrodes, gold-plated sites exhibited a nearly 5-fold smaller $\mathrm{H}_{2} \mathrm{O}_{2}$ sensitivity than an unplated $\mathrm{Pt} / \mathrm{Ir}$ surface (Figure S1). Remarkably, following this first step, gold-plated sites could be rendered $\mathrm{H}_{2} \mathrm{O}_{2}$ sensitive upon mild platinization. In enzyme-coated electrodes, there was a nearly 10 -fold difference in $\mathrm{H}_{2} \mathrm{O}_{2}$ oxidation currents between $\mathrm{Au}$ and $\mathrm{Au} / \mathrm{Pt}$ sites at 0.4-0.6 V vs. $\mathrm{Ag} / \mathrm{AgCl}$ (Figure 1B). The increase in $\mathrm{Au}$ sites' response to $\mathrm{H}_{2} \mathrm{O}_{2}$ above $+0.7 \mathrm{~V}$ is in agreement with the electrochemical behavior of a pure Au electrode and probably results from the formation of surface oxides (Burke and 
1 Nugent, 1997; O’Neill et al., 2004). Interestingly, the response of $\mathrm{Au} / \mathrm{Pt}$ electrodes to $\mathrm{H}_{2} \mathrm{O}_{2}$ was higher

2 than that of unplated electrodes (Figure S1), possibly reflecting an increase in the electrode surface

3 area and/or an electrocatalytic effect caused by the deposition of nanostructured platinum over the

4 gold surface (Burke, 1996; Domínguez-Domínguez et al., 2008). Even when using common-mode

5 rejection, decreasing the magnitude of interferences in individual sites is desirable. Thus, after plating

6 and coating the tetrode, we electropolymerized $m$-PD in two of the recording sites, in order to reduce

7 responses to electroactive compounds larger than $\mathrm{H}_{2} \mathrm{O}_{2}$ (eg. ascorbate or dopamine) (Hascup et al.,

8 2013; Santos et al., 2008). The final TACO sensor configuration consisted of all possible

9 combinations of $\mathrm{Pt}$ and $m$-PD modifications of Au-plated recording sites (Figure 1A).

10 The responses of TACO sensors' sites to $\mathrm{Ch}, \mathrm{H}_{2} \mathrm{O}_{2}$ and to compounds that can potentially interfere during in vivo measurements were tested by step additions in the beaker at $+0.6 \mathrm{~V}$ vs. $\mathrm{Ag} / \mathrm{AgCl}$ (Figure $1 \mathrm{C}$, top). In accordance with the voltammograms of $\mathrm{H}_{2} \mathrm{O}_{2}$ sensitivities (Figure 1B), the responses of TACO sensors' gold-plated sites to $\mathrm{Ch}$ and $\mathrm{H}_{2} \mathrm{O}_{2}$ were much lower than those of platinized sites. On average, like for $\mathrm{H}_{2} \mathrm{O}_{2}$, this difference was about 10 -fold for $\mathrm{Ch}$, regardless of $m$-PD electropolymerization (Figure 1D). Contrasting with its lack of effect on Ch sensitivity, $m$-PD dramatically decreased responses to ascorbate and dopamine, regardless of the site's metal composition (Figure 1E). In addition, we have also calibrated the impedance of recording sites at low frequency by applying a low-amplitude $0.2 \mathrm{~Hz}$ AC voltage on top of the DC offset. This low frequency is of particular relevance, as it overlaps with putative phasic cholinergic dynamics previously reported by us and other groups in anesthetized and freely-moving rodents (Howe et al., 2017; Parikh et al., 2007; Santos et al., 2015; Teles-Grilo Ruivo et al., 2017). Impedances calculated from the current oscillations generated by the $\mathrm{AC}$ voltage (Figure $1 \mathrm{C}$, bottom) were comparable across all sites (Figure 1E). Collectively, the results summarized in Figure 1E and Table 1 validate the gold-plating approach to produce pseudo-sentinel sites, as it selectively reduces electrode's response to $\mathrm{H}_{2} \mathrm{O}_{2}$. As compared to our previous stereotrode design using $50 \mu \mathrm{m}$ diameter wires, these sensors keep the same in vitro performance, with a limit of detection (LOD) in the low nanomolar range and $T_{50}$ response times around $1.5 \mathrm{~s}$ (Table 1), which is remarkable for such small electrode surfaces. Additionally, while $m$-PD abrogates the response of electropolymerized sites to large electroactive molecules, the differential site modifications might provide further information on the signal identity. Allied to multivariate methods of analysis, the differential sites' responses to different factors can potentially be exploited and electrochemical tetrode designed employed in TACO sensor can be generalized to other types of sensors. 
A
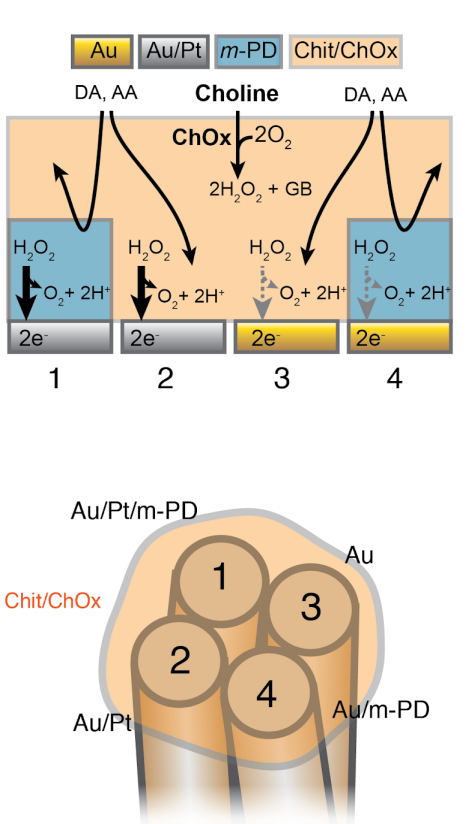

D

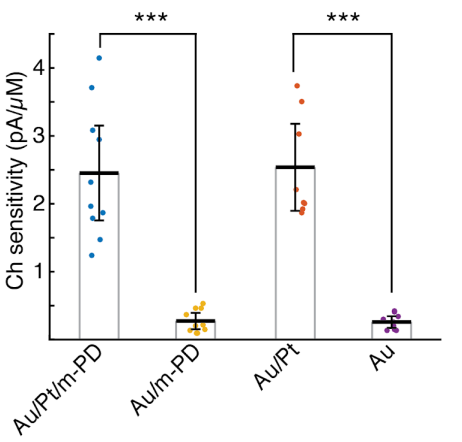

B

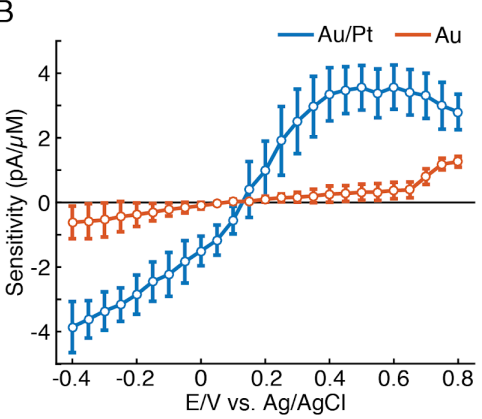

C

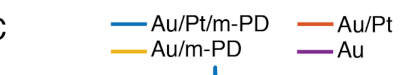

E
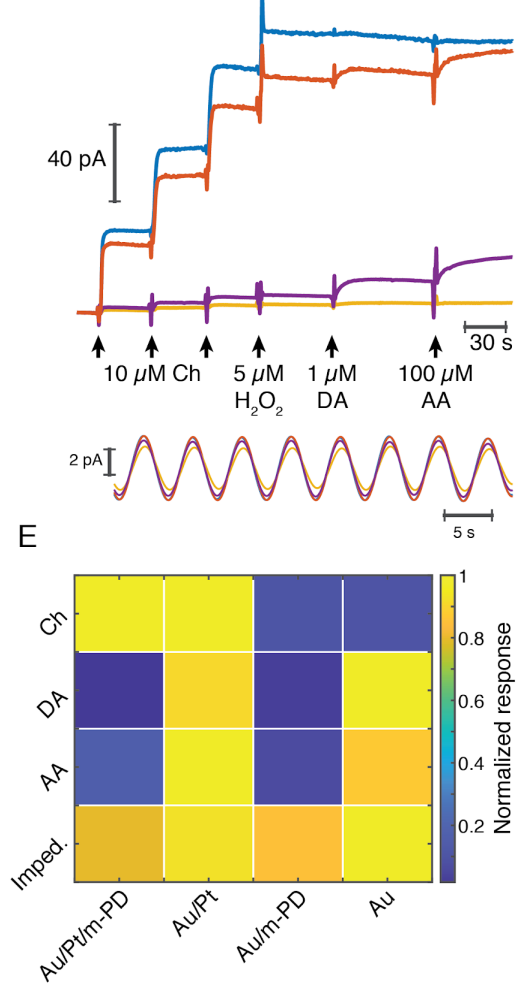

Figure 1. TACO sensor response properties and application in behaving animals. (A) Schematics depicting the multichannel biosensor design. (B) Voltammogram showing $\mathrm{H}_{2} \mathrm{O}_{2}$ sensitivities of gold-plated and platinized sites upon amperometric calibrations at different DC potentials $(n=10)$. Prior to calibrations, the tetrodes were coated with a matrix of chitosan/ChOx. (C) Top shows a representative calibration of a sensor showing the response of different types of sites to step additions of $\mathrm{Ch}, \mathrm{H}_{2} \mathrm{O}_{2}$, dopamine (DA) and ascorbate (AA). Bottom shows an example of current responses of sensor sites to a sinusoidal $12 \mathrm{mV}$ AC voltage at $0.2 \mathrm{~Hz}$ overlaid on top of $+0.6 \mathrm{~V}$ vs. $\mathrm{Ag} / \mathrm{AgCl} \mathrm{DC}$ voltage. The current $\mathrm{AC}$ amplitudes were used to calculate electrodes' impedances at $0.2 \mathrm{~Hz}$. (D) Sensitivities of different types of sites towards $\mathrm{Ch}$ ( $\mathrm{n}=10$ biosensors). Unlike $m$-PD electropolymerization, platinization significantly increased sensitivity $(\mathrm{p}<0.0001$ and $F=115$ for platinization effect and $\mathrm{p}=0.87$ and $F=0.03$ for $m$-PD, by two-way ANOVA for unbalanced data). (E) Normalized responses of each tetrode site to $\mathrm{Ch}$, interferent molecules and voltage, presented as impedance at $0.2 \mathrm{~Hz}(\mathrm{n}=5-10)$. Magnitudes significantly depended on the site modification and on the factor tested $(\mathrm{p}<0.0001$ and $F=22$ for platinization, $F=109$ for $m$-PD and $F=12.9$ for factors, by three-way ANOVA for unbalanced data). Platinization selectively increased responses to $\mathrm{Ch}(\mathrm{p}<0.0001)$ while $m$-PD decreased responses only to DA and AA $(p<0.0001)$. Impedances did not significantly differ across different types of electrode modifications $(p>0.99)$. Groups were compared by three-way ANOVA followed by Tukey-Kramer post-hoc tests. 
Table 1. Analytical properties of TACO sensors

Individual sites' analytical properties

\begin{tabular}{|c|c|c|c|c|c|c|}
\hline Channel type & $\begin{array}{c}\text { Ch sensitivity } \\
(\mathbf{p A} / \mu \mathrm{M})\end{array}$ & $\begin{array}{l}\text { Ch sensitivity } \\
\left(\mathrm{nA} \mu \mathrm{M}^{-1} \mathrm{~cm}^{-2}\right)\end{array}$ & $\begin{array}{c}\mathrm{H}_{2} \mathrm{O}_{2} \\
\text { sensitivity } \\
(\mathrm{pA} / \mu \mathrm{M})\end{array}$ & $\begin{array}{c}\text { DA sensitivity } \\
(\mathbf{p A} / \mu \mathrm{M}) \\
\text { selectivity } \\
\text { ratio }\end{array}$ & $\begin{array}{c}\text { AA sensitivity } \\
(\mathbf{p A} / \mu \mathrm{M}), \\
\text { selectivity } \\
\text { ratio }\end{array}$ & 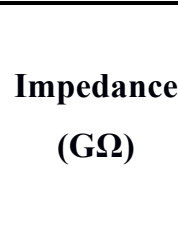 \\
\hline $\mathrm{Au} / \mathrm{Pt}-\mathrm{mPD}$ & $\begin{array}{c}2.45 \pm 0.70 \\
(n=10)\end{array}$ & $\begin{array}{c}1081 \pm 309 \\
(\mathrm{n}=10)\end{array}$ & $\begin{array}{c}2.48 \pm 0.93 \\
(\mathrm{n}=8)\end{array}$ & $\begin{array}{c}0.15 \pm 0.23 \\
>4.6(\mathrm{n}=10)\end{array}$ & $\begin{array}{l}0.02 \pm 0.013 \\
>53(\mathrm{n}=10)\end{array}$ & $\begin{array}{c}2.90 \pm 0.48 \\
(\mathrm{n}=5)\end{array}$ \\
\hline $\mathrm{Au} / \mathrm{Pt}$ & $\begin{array}{c}2.54 \pm 0.64 \\
(\mathrm{n}=8)\end{array}$ & $\begin{array}{c}1118 \pm 283 \\
(\mathrm{n}=8)\end{array}$ & $\begin{array}{c}2.86 \pm 1.10 \\
(n=6)\end{array}$ & $\begin{array}{r}7.48 \pm 1.86 \\
>0.2(\mathrm{n}=8)\end{array}$ & $\begin{array}{c}0.22 \pm 0.20 \\
>4.4(\mathrm{n}=8)\end{array}$ & $\begin{array}{c}3.38 \pm 0.56 \\
(\mathrm{n}=5)\end{array}$ \\
\hline Au-mPD & $\begin{array}{c}0.27 \pm 0.12 \\
(\mathrm{n}=10)\end{array}$ & $\begin{array}{c}118.2 \pm 53 \\
(\mathrm{n}=10)\end{array}$ & $\begin{array}{c}0.22 \pm 0.16 \\
(\mathrm{n}=8)\end{array}$ & $\begin{array}{c}0.13 \pm 0.23 \\
>0.41(\mathrm{n}=10)\end{array}$ & $\begin{array}{l}0.007 \pm 0.004 \\
>14(\mathrm{n}=10)\end{array}$ & $\begin{array}{c}3.11 \pm 0.77 \\
(\mathrm{n}=5)\end{array}$ \\
\hline $\mathrm{Au}$ & $\begin{array}{c}0.25 \pm 0.086 \\
(\mathrm{n}=9)\end{array}$ & $\begin{array}{c}111.5 \pm 38 \\
(\mathrm{n}=10)\end{array}$ & $\begin{array}{c}0.29 \pm 0.08 \\
(\mathrm{n}=7)\end{array}$ & $\begin{array}{c}8.24 \pm 1.84 \\
>0.017(\mathrm{n}=9)\end{array}$ & $\begin{array}{c}0.19 \pm 0.16 \\
>0.48(\mathrm{n}=9)\end{array}$ & $\begin{array}{c}3.65 \pm 0.59 \\
(\mathrm{n}=5)\end{array}$ \\
\hline
\end{tabular}

Whole sensor's analytical properties

\begin{tabular}{|c|c|}
\hline Limit of detection (nM) & Response time (s) \\
\hline $28 \pm 0.011(\mathrm{n}=10)$ & $1.4 \pm 0.4(\mathrm{n}=10)$ \\
\hline
\end{tabular}

The data are given as the mean \pm CI $(95 \%)$

The number of sensors tested is given in parentheses. 
1 Application of the TACO sensor in freely-moving rodents highlights the 2 benefits of optimal suppression of confounding sources

3 In order to test the capacity of the TACO sensor to achieve artifact-free measurements of fast COA 4 transients in behaving animals, we have first performed recordings in freely-moving animals. We 5 implanted a TACO sensor in the rat brain, which was progressively lowered until it reached the 6 hippocampal CA1 pyramidal layer, using a microdrive. Since the measurement of fast and local LFP7 related patterns could potentially be affected by the enzyme coating, we concurrently recorded LFP 8 from a 32-channel linear silicon probe implanted in the proximity of the biosensor. Extracellular electrophysiology allowed us to validate the amperometric measurement of high-frequency LFPrelated profiles while gathering multi-layer hippocampal network dynamics (Figure 2A, left). The COA signal was cleaned by subtraction of the pseudo-sentinel from the Ch-sensing sites' signal, upon frequency-domain correction of the pseudo-sentinel amplitude and phase (please see Methods) (Santos et al., 2015). This procedure led to substantial removal of fast current fluctuations ascribed to LFP (example recording in Figure 2A, top right). Accordingly, the mean spectral power at $\sim 1-20 \mathrm{~Hz}$ of the signal derived from the $\mathrm{Au} / \mathrm{Pt} / \mathrm{m}$-PD site during both NREM sleep and wake periods decreased more than two orders of magnitude after the signal cleaning procedure (Figure 2A, bottom right). The cleaned COA signal tonically changed across different brain states reaching higher values during active wakefulness and REM sleep than during NREM sleep, which corroborates previous measurements of brain state-dependent ACh levels (Hasselmo and McGaughy; Marrosu et al., 1995) (Figure 2B and C). Remarkably, on top of tonic brain-state-related dynamics, COA fluctuated on the time-scale of seconds, suggesting the possibility of a rich phasic cholinergic dynamics within each brain state.

Acetylcholine can suppress the occurrence of SWRs (Norimoto et al., 2012; Vandecasteele et al., 2014) and positively correlates with arousal (Hasselmo and McGaughy; Marrosu et al., 1995; Reimer et al., 2016; Teles-Grilo Ruivo and Mellor, 2013; Teles-Grilo Ruivo et al., 2017), which typically coincides with hippocampal theta oscillations and manifests as locomotion in freely-moving animals (Buzsáki, 2002; Gu et al., 2017). Thus we tested whether these events could correlate with fast changes in putative cholinergic activity reflected by COA. hippocampal SWRs were detected from a silicon probe site in the CA1 pyramidal layer during NREM sleep. Average raw biosensor signals triggered on the peak of SWRs showed a prominent peak in all TACO sensor's sites (Figure 2D, top). The similarity of peak amplitudes suggests an LFP-related origin of these currents, which was virtually absent in the cleaned signals (Figure, 2D, middle), and reflects the slow profile of the sharp wave. The high magnitude of this LFP signal contaminating COA measurements emphasizes the importance of the common-mode rejection approach in revealing putative cholinergic dynamics that would otherwise be masked. Interestingly, regardless of $m$-PD electropolymerization, putative $\mathrm{Ch}$ 
1 differential signals showed a peak lagging the SWR by $\sim 3 \mathrm{~s}$. Importantly, this peak was not present in

2 pseudo-sentinel sites, supporting an authentic change in COA (Figure 2D, top and middle).

3 In our recordings, high-frequency bursts captured with electrophysiology and amperometry typically

4 coincided in time and exhibited similar spectral features (Figure S2A). Accordingly, the continuous

5 power-power correlation between amperometry-derived current and silicon probe-derived LFP was

6 high ( $>0.7$, Figure S2B) across a wide frequency range. The very similar average power spectra

7 triggered to SWRs (Figure 2D, bottom and Figure S2C) and the high co-occurrence of SWRs detected

8 with both modalities (Figure S2D) further prove the ability of our amperometric system to reliably

9 record high-frequency LFP-related currents. Although theoretically expected, this capability has not

10 been experimentally documented before.

11 Bouts in locomotion, detected as peaks in the rat running speed, were associated with transient

12 increases in theta power and were also followed by a peak in putative $\mathrm{Ch}$ signal, observed in the clean

13 biosensor signal but not in the pseudo-sentinel subtraction control (Figure 2E).

14 These results highlight the usefulness of our multichannel pseudo-sentinel approach to discriminate 15 between authentic changes in COA and interferent signals in the brain. Notably, phasic changes in 16 COA were associated with transient changes in arousal or exploratory behavior and with SWRs, events that are critical for memory encoding and consolidation, respectively (Buzsáki, 2002, 2015). 

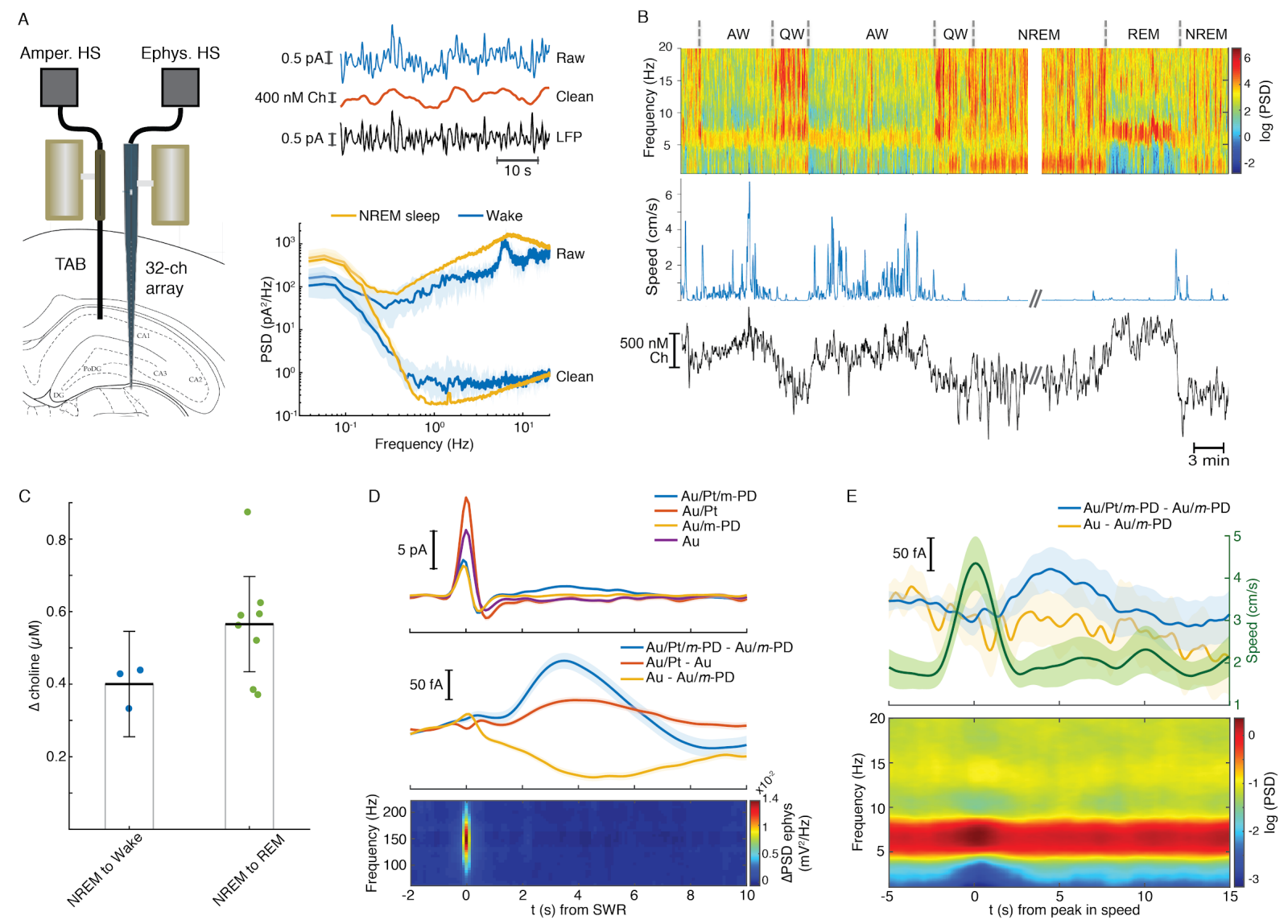

1 Figure 2. TACO sensor application in freely-behaving animals. (A) Left panel depicts the arrangement of a multichannel ChOx biosensor and a 32-channel silicon probe chronically implanted in the hippocampus of a rat.

3 Both probes were attached to microdrives. Top right panel shows a segment of a raw signal (low-pass filtered at $4 \quad 1 \mathrm{~Hz}$ ) and the resulting clean putative Ch and LFP components upon common-mode rejection, recorded during 5 NREM sleep. The plot in the bottom right illustrates the dramatic decrease in the spectral power upon cleaning the signal by common-mode rejection both during wake $(n=10)$ and NREM sleep periods $(n=19)$. (B) Representative recording across multiple brain states showing power spectrogram from a silicon probe site at hippocampal fissure (top), rat speed (middle) and clean ChOx signal (bottom). (C) Change in tonic putative $\mathrm{Ch}$ levels following transitions from NREM sleep to wake $(n=3)$ or REM sleep $(n=9)$. Both groups were significantly different from zero $(\mathrm{p}<0.05$, inferred from one-way anova followed by Tukey-Kramer post-hoc analysis). (D) Average low frequency (1 $\mathrm{Hz}$ low-pass filtered) biosensor signals and high frequency power spectrograms triggered to SWRs detected from a silicon probe channel in CA1 pyramidal layer $(\mathrm{n}=8074)$. Responses from biosensor sites are shown before (top) and after (middle) common-mode rejection. Average spectrogram was obtained from the silicon probe site used to detect SWRs (bottom). (E) Average speed, biosensor signals following common-mode rejection and LFP power spectrogram triggered to peaks in rat speed in an open-field arena ( $\mathrm{n}=127$, top). The spectrogram was derived from hippocampal fissure LFP (bottom). 
1 Phasic biosensor responses during locomotion bouts correlate with oxygen

\section{2 transients}

3 TACO sensor offers the opportunity to study cholinergic activity with unprecedented spatial 4 resolution and selectivity in behaving animals. However, since $\mathrm{O}_{2}$ is a co-substrate of oxidases, sensitivity to physiological $\mathrm{O}_{2}$ variations is a potential issue of this type of biosensors (Baker et al., 2015; Chatard et al., 2018; Dixon et al., 2002; McMahon et al., 2007; Santos et al., 2015). To control for $\mathrm{O}_{2}$-related signals in vivo, we have exploited the advantages of the tetrode configuration, ideally suited to measure multiple electroactive compounds at the same brain spot. Furthermore, bias on the impedance and response time across the recording sites is minimal since the same enzyme immobilization matrix covers the whole tetrode tip. Using a new customized head-stage allowing independent control of the potential applied on each recording site, we have simultaneously measured $\mathrm{O}_{2}$ and COA with the same sensor. Oxygen measurement was achieved by $\mathrm{O}_{2}$ reduction on a goldplated site at a negative potential, which was typically maximal at $-0.4 \mathrm{~V}$ vs. $\mathrm{Ag} / \mathrm{AgCl}$ (Figure $3 \mathrm{~A}$, left). To avoid electrical cross-talk between tetrode sites, sporadically observed when we applied a high negative voltage to one site, we set $-0.2 \mathrm{~V}$ vs. $\mathrm{Ag} / \mathrm{AgCl}$ as the standard voltage for in vivo $\mathrm{O}_{2}$ measurements. Although the gold-plated site could also reduce $\mathrm{H}_{2} \mathrm{O}_{2}$, the very low response magnitude as compared to $\mathrm{O}_{2}$ (Figure $3 \mathrm{~A}$, left) assured a negligible contribution of $\mathrm{H}_{2} \mathrm{O}_{2}$ generated by immobilized ChOx to the $\mathrm{O}_{2}$ signal recorded in vivo. Under this configuration (Figure 3A, bottom), clean $\mathrm{COA}$ and $\mathrm{O}_{2}$ signals were obtained by subtraction of $\mathrm{Au} / \mathrm{Pt} / m-\mathrm{PD}($ at $+0.6 \mathrm{~V})$ and $\mathrm{Au}($ at $-0.2 \mathrm{~V}$ ) by the $p s e u d o$-sentinel $m$-PD site, respectively.

In order to obtain more controlled experimental conditions and overcome technical constraints posed by the size of the head-stage, the remaining experiments were performed in head-fixed mice spontaneously running on a treadmill (Figure 3A bottom). Strikingly, we found that phasic COA dynamics typically matched the simultaneously recorded $\mathrm{O}_{2}$ fluctuations, which were generally related to changes in behavioral state (Figure 3B). In line with the freely-moving data (Figure 2E), head-fixed running bouts were temporally correlated with an increase in the power of theta oscillations as well as with delayed phasic increases in both $\mathrm{COA}$ and $\mathrm{O}_{2}$, peaking a few seconds later (Figure 3B and C). This lag was significantly greater than zero in all recording sessions (two-sample $t$-test, $\mathrm{p}<0.01)$, averaging $3.85 \pm 2.04 \mathrm{~s}(\mathrm{n}=5)$ for $\mathrm{COA}$ and $5.04 \pm 3.12 \mathrm{~s}(\mathrm{n}=5)$ for $\mathrm{O}_{2}$. Notably, running-related isolated $\mathrm{COA}$ or $\mathrm{O}_{2}$ peaks were rare, with the vast majority of the events showing either no identifiable change or co-occurrence of the two transients (Figure 3D). Amplitudes of COA peaks were significantly correlated with those of $\mathrm{O}_{2}(\mathrm{p}<0.001)$ when pooling together the events from all recordings, which allowed sampling across the full $\mathrm{O}_{2}$ amplitude range (Figure 3E). Phasic COA correlated more consistently with $\mathrm{O}_{2}$ than with theta power or speed (Figure 3F). Moreover, runningbout-related $\mathrm{COA}$ and $\mathrm{O}_{2}$ peak lags were significantly correlated $(\mathrm{p}<0.001$, Figure $3 \mathrm{G})$ and, interestingly, within most sessions ( 3 out of 5), COA peaked significantly earlier than $\mathrm{O}_{2}(\mathrm{p}<0.05)$. 

made available under aCC-BY 4.0 International license.

1 In summary, these results indicate a strong correlation between phasic COA and $\mathrm{O}_{2}$ in the 2 hippocampus of head-fixed mice following locomotion bouts.

3 
A
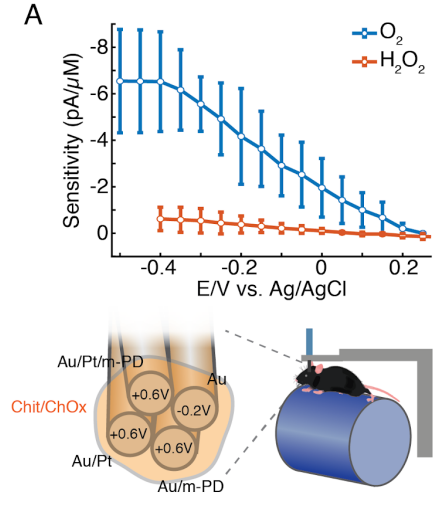

C

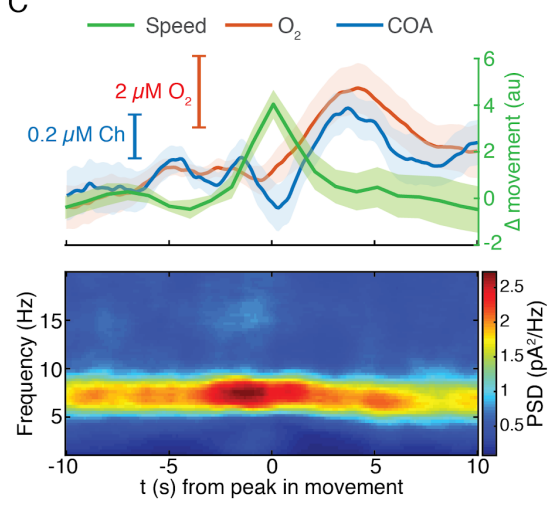

D
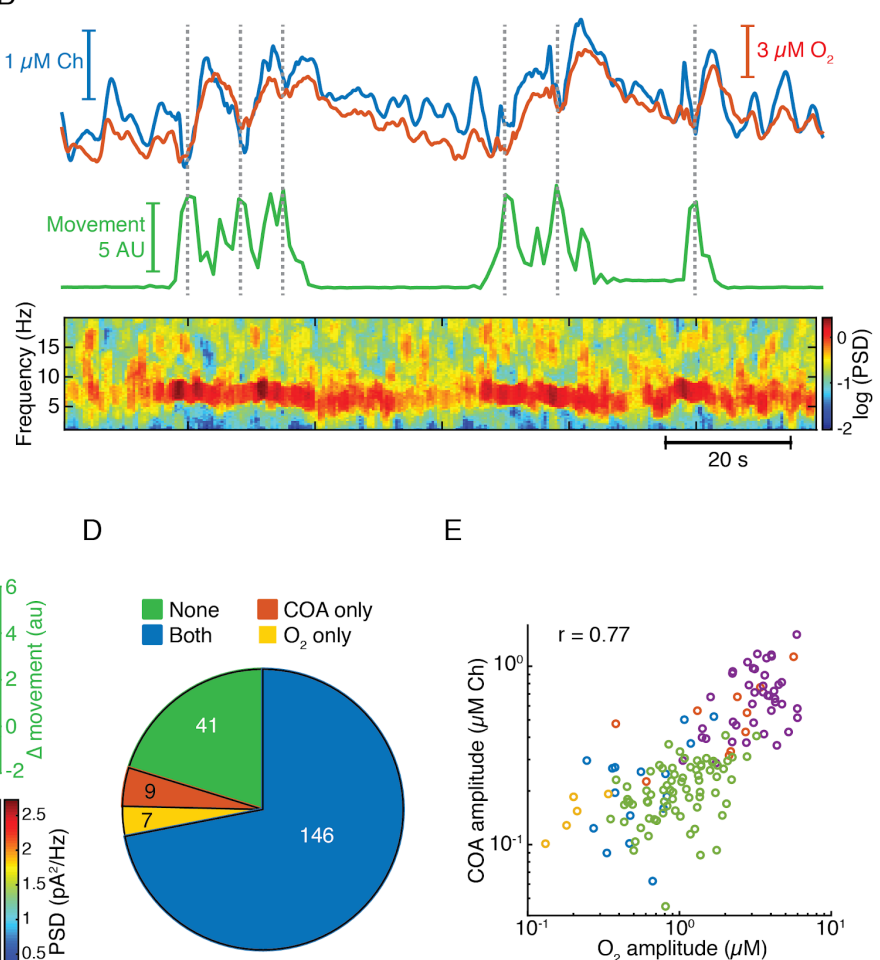

E

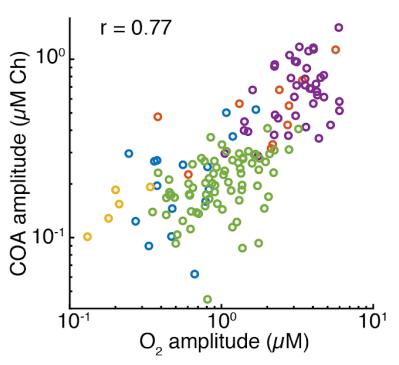

$$
\text { F }
$$

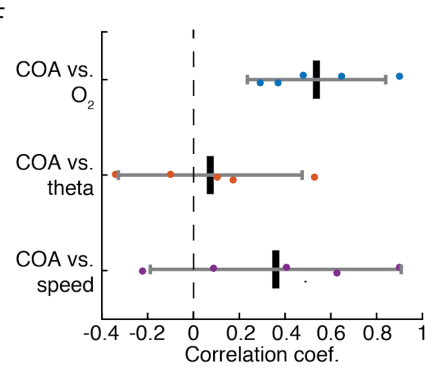

G

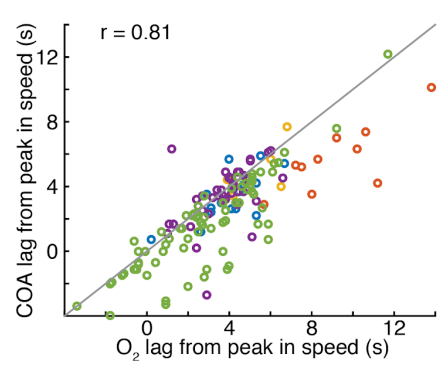

Figure 3. Locomotion-related correlated changes in $\mathrm{COA}$ and local oxygen concentration in head-fixed mice. (A) The voltammogram shows the DC voltage-related sensitivity of gold-plated sites towards $\mathrm{H}_{2} \mathrm{O}_{2}$ and $\mathrm{O}_{2}$ (top). The schematics shows the tetrode configuration used to simultaneously measure $\mathrm{H}_{2} \mathrm{O}_{2}$ resulting from COA and extracellular $\mathrm{O}_{2}$ (bottom left). Values on each recording site indicate the applied DC voltage vs. $\mathrm{Ag} / \mathrm{AgCl}$ ( $+0.6 \mathrm{~V}$ for $\mathrm{H}_{2} \mathrm{O}_{2}$ and $-0.2 \mathrm{~V}$ for $\mathrm{O}_{2}$ measurements). Schematics of the head-fixed setup (bottom right). (B) Representative data segment of simultaneous recording of COA and $\mathrm{O}_{2}$ (top), locomotion speed (middle) and LFP spectrogram(bottom). Dashed lines indicate the times of detected locomotion bouts. (C) Average speed, COA and $\mathrm{O}_{2}$ profiles (top) and LFP power spectrogram bottom) triggered to locomotion bouts ( $\mathrm{n}=41$ from one recording session). (D) Event counts across different categories, distinguished by the occurrence or absence of $\mathrm{ChOx}$ and/or $\mathrm{O}_{2}$ peaks following locomotion bouts. Data was collected from 5 recording sessions in 3 mice. (E) Amplitude of ChOx (shown as calibrated Ch concentrations) vs $\mathrm{O}_{2}$ transients following locomotion bouts (data from the events that had increases in both signals, $n=146$ ). Each color represents one recording session ( $n=5-74$ events per recording). Amplitudes were significantly correlated $\left(r_{\text {spearman }}=0.77, p<0.001\right)$. (F) Spearman correlation coefficients between ChOx activity amplitudes and $\mathrm{O}_{2}$, theta power or speed $(n=5)$. Correlation across recordings was significantly above zero for ChOx $v s \mathrm{O}_{2}$ data $(\mathrm{p}<0.01, t$-test). Each point represents a single recording session. $(\mathrm{G})$ Lags of ChOx peaks vs. $\mathrm{O}_{2}$ peak lags relative to the peak in speed. The correlation between variables was significant $\left(\mathrm{r}_{\text {spearman }}=0.81, \mathrm{p}<0.001, \mathrm{n}=146\right)$. Each color represents one recording session ( $\mathrm{n}=5-74$ events per recording). The diagonal line was plotted to ease the comparison between lags. 
1 Phasic COA and oxygen signals follow clusters of sharp-wave/ripples during

2 immobility

3 Hippocampal SWRs are critical for memory consolidation and their occurrence has been proposed to

4 be anti-correlated with cholinergic activity in the hippocampus (Hasselmo and McGaughy; Norimoto

5 et al., 2012; Vandecasteele et al., 2014). However, our freely-moving data showing COA transients

6 following SWRs contradicts this prediction, posing questions on the factors driving the biosensor

7 response during these events. Thus, we investigated whether the SWR-related response of

8 immobilized ChOx was correlated with extracellular $\mathrm{O}_{2}$ in head-fixed mice during periods of

9 quiescence.

10 Remarkably, on average, SWR events were followed by fast transients in both COA and $\mathrm{O}_{2}$ (Figure

$114 \mathrm{~A}$ ). Both $\mathrm{COA}$ and $\mathrm{O}_{2}$ peak amplitudes correlated best with ripple power integrated over a period of

$12 \sim 2$ seconds lagging them by 3-4 seconds (Figure 4B and C). Similarly, both SWR count and summed

13 ripple power integrated in a 2 -second window positively correlated with the delayed amplitude of

14 both $\mathrm{COA}$ and $\mathrm{O}_{2}$ transients (Figure 4D-E and Figure $\mathrm{S} 3$ ).

15 These findings might indicate the contribution of a time-constant related to the sensor response and/or

16 to a relatively slow physiological process by which SWRs recruit cholinergic activity or a local

17 hemodynamic response leading to $\mathrm{O}_{2}$ increase. Indeed, functional MRI has reported SWR-triggered

18 increases in BOLD signal in the primate hippocampus, reflecting a local tissue hemodynamic

19 response at a time-scale matching $\mathrm{O}_{2}$ transients observed here (Ramirez-Villegas et al., 2015).

20 Importantly, the amplitudes of SWR-associated COA and $\mathrm{O}_{2}$ phasic transients were consistently

21 correlated within all recordings $(n=3, p<0.001$, Figure $4 F)$. Similarly, lags of these transients to SWR

22 were significantly correlated (Figure 4G, H, I).

23 Together, the data indicate correlated phasic profiles of COA and extracellular $\mathrm{O}_{2}$ in response to SWRs (Figure 4I), especially when they happen in clusters. As in the case of locomotion bouts, at this stage one could not rule out the contribution of neither phasic $\mathrm{Ch}$ or $\mathrm{O}_{2}$ as the trigger for the peaks in COA. The putative cholinergic origin of this response would, nevertheless, be surprising given the suppressive effect of ACh on SWR occurrence (Norimoto et al., 2012; Vandecasteele et al., 2014). Thus, in light of the $\mathrm{O}_{2}$ transients that accompany the rise in COA, these observations cast doubt on the validity of the putative SWR-triggered cholinergic response. 


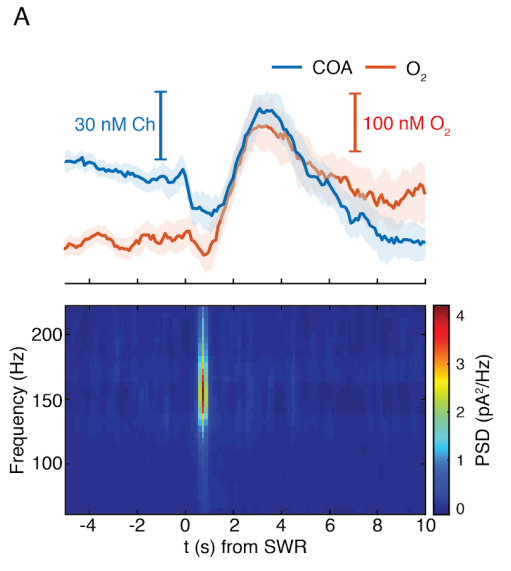

B
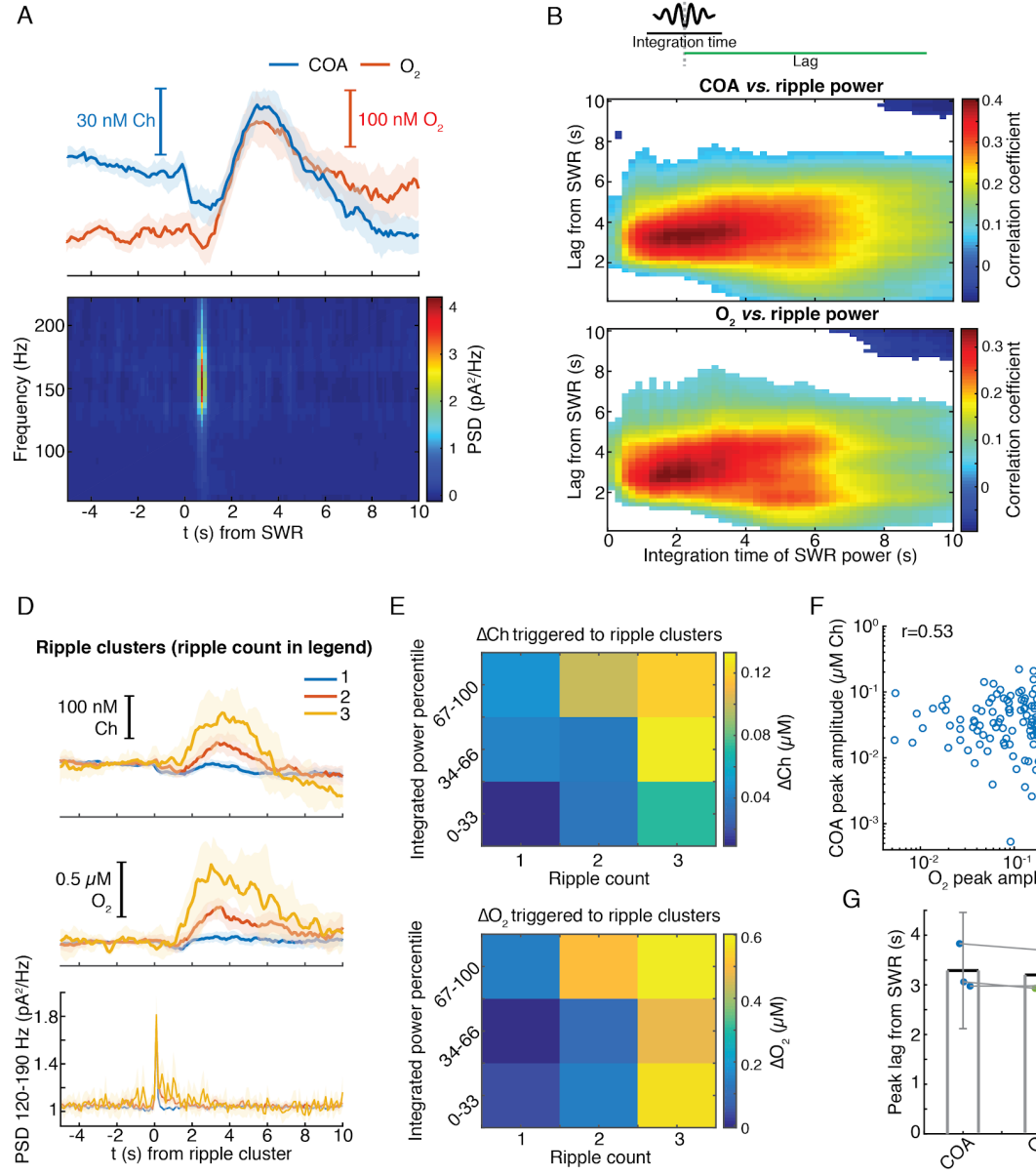

$E$
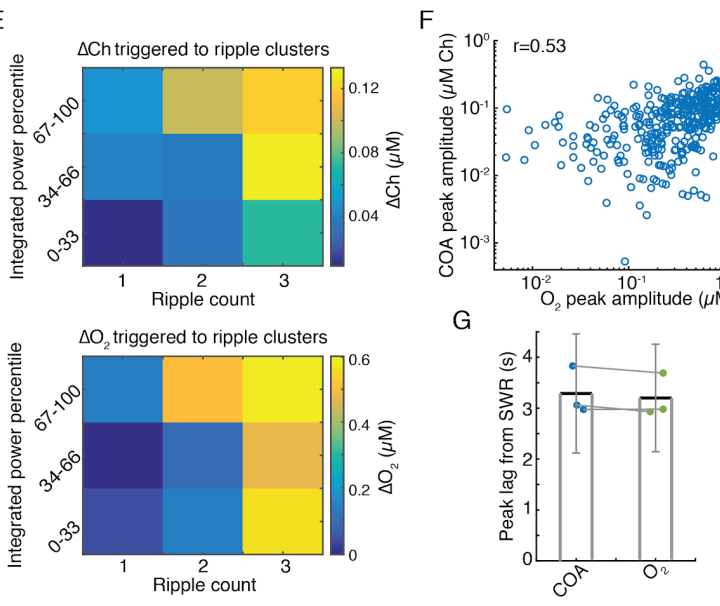
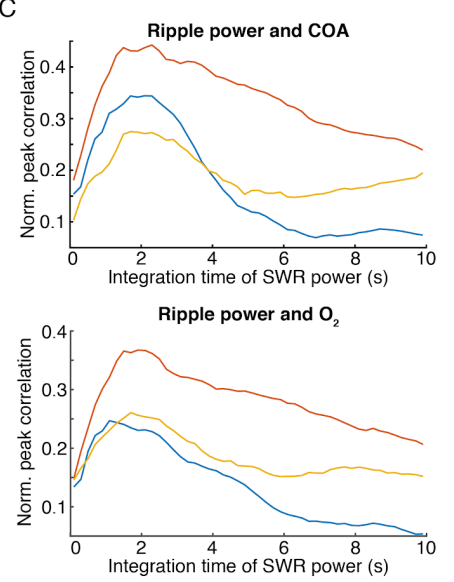

$\mathrm{H}$
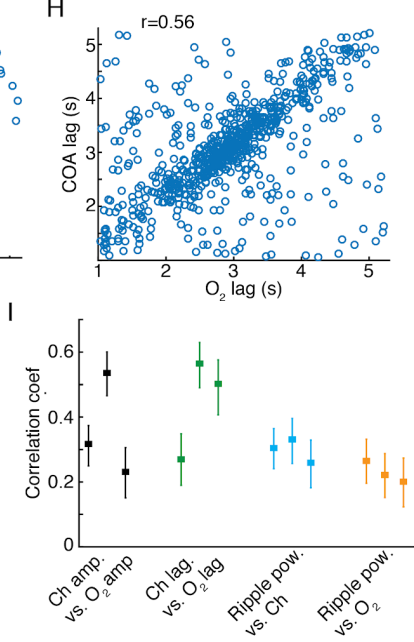

Figure 4. Correlated COA and oxygen dynamics associated with hippocampal SWRs. (A) Average ChOx and $\mathrm{O}_{2}$ dynamics triggered to hippocampal SWRs $(\mathrm{n}=1067)$ in the head-fixed setup (top) and average LFP spectrogram (bottom). (B) Pseudo-color-coded Spearman correlation between ChOx (top) or $\mathrm{O}_{2}$ (bottom) amplitude at different time lags from SWRs (y-axis) and integrated ripple band power computed in windows of varying size ( $x$-axis) for a representative session. White areas represent non-significant correlations $(p>0.05)$. (C) Normalized peak correlations, obtained from the difference between maximal and minimal correlations for each integration time in $\mathrm{B}$, between integrated ripple power and ChOx activity or $\mathrm{O}_{2}$. Colors represent recording sessions in different mice. (D) Average COA, $\mathrm{O}_{2}$ and ripple power dynamics triggered to SWRs bursts containing variable number of SWRs (1-3) in a $2 \mathrm{~s}$ window ( $\mathrm{n}=34-591$ SWRs in each group, respectively from one representative session). (E) Peak amplitude of ChOx activity or $\mathrm{O}_{2}$ transients as a function of SWR burst size (as shown in D) sorted by different percentile ranges of summed ripple power (same data as in D). Both SWR count and total ripple power significantly affected the amplitude of $\mathrm{ChOx}$ and $\mathrm{O}_{2}$ (two-way ANOVA for unbalanced data following ART, $p<0.0001$ and $F>12$ for both factors in $\mathrm{ChOx}$ and $\mathrm{O}_{2}$ data). (F) Amplitude of ChOx vs. $\mathrm{O}_{2}$ transients following SWRs from one recording session $\left(\mathrm{r}_{\text {spearman }}=0.53, \mathrm{p}<0.0001, \mathrm{n}=1067\right)$. $(\mathrm{G})$ Group statistics on the lags of $\mathrm{ChOx}$ and $\mathrm{O}_{2}$ peaks relative to SWRs. Each dot is the average from one recording. Bars represent means $\pm \mathrm{CI}$. $(\mathrm{H})$ Lags of ChOx peaks as a function of $\mathrm{O}_{2}$ peak lags relative to SWRs. The parameters were significantly correlated $\left(\mathrm{r}_{\text {spearman }}=0.56, \mathrm{p}<0.0001, \mathrm{n}=1067\right)$. (I) Summary of correlations between sensor signals and ripples. Each point represents one recording session, and error bars are CIs computed using bootstrap. 


\section{Interactions between COA and oxygen are not sensitive to ongoing}

\section{2 hippocampal dynamics and depend on the time-scale}

3 The correlation between $\mathrm{COA}$ and $\mathrm{O}_{2}$ following locomotion and SWRs may reflect interaction

4 between the two signals or result from the coincident recruitment of cholinergic and hemodynamic

5 responses. While a consistent relationship between the two variables is expected in the first case,

6 irrespective of ongoing network dynamics, the same may not happen in the latter. To get insights into

7 this question, we analyzed an additional category of events, consisting of fast $\mathrm{O}_{2}$ transients detected

8 outside the time-windows surrounding SWRs and peaks in locomotion. Under this condition, the

9 average rate of $\mathrm{O}_{2}$ peaks occurrence was only $18 \%$ of the rate computed from total $\mathrm{O}_{2}$ peaks (Figure S4A), emphasizing the strong modulatory effect of hemodynamics and respiration on $\mathrm{O}_{2}$, potentially evoked by SWRs and locomotion, respectively (Leithner and Royl, 2014; Ramirez-Villegas et al., 2015; Zhang et al., 2019). Remarkably, virtually all (>95\%) of these events had an associated COA transient. The dynamics of COA and $\mathrm{O}_{2}$ were typically similar (Figure 5A), with COA peaks lagging, on average, from $-0.09 \mathrm{~s}$ to $0.48 \mathrm{~s}$ ( $\mathrm{n}=3$ recordings) relative to $\mathrm{O}_{2}$. Signal amplitudes were significantly correlated both when pooling together all events $(p<0.001$, Figure $5 B)$ or within all individual sessions $(\mathrm{p}<0.01)$. The amplitude correlation coefficients were in the range of those obtained for $\mathrm{O}_{2}$ peaks associated with locomotion and SWRs (Figure 5C), but the average amplitudes of $\mathrm{O}_{2}$ and corresponding COA signals were in the sub-micromolar range, comparable to those associated with SWRs (Figure 5D). Overall, although the amplitude range of locomotion-related peaks was wider, it is notable that the whole data fit to a $\mathrm{COA} / \mathrm{O}_{2}$ relationship that seems to follow the same model across recordings and event types (Figure 5D). These observations are therefore compatible with an interaction between $\mathrm{COA}$ and $\mathrm{O}_{2}$, although contribution of third-party factors could not be definitely excluded at this stage.

Besides the amplitude of $\mathrm{O}_{2}$ transients, the temporal profile of $\mathrm{O}_{2}$ rise might influence the shape and amplitude of associated $\mathrm{ChOx}$ responses and thus provide further hints on the causality and directionality of $\mathrm{COA}-\mathrm{O}_{2}$ interactions. Thus, we detected $\mathrm{O}_{2}$ peaks at different frequency bands (ignoring their correlation with SWRs or speed), resulting in a spectrum of $\mathrm{O}_{2}$ rise times from less than 2 to $14 \mathrm{~s}$ (please see Methods section for details). Across all recording sessions, we consistently observed that the COA peak anticipated $\mathrm{O}_{2}$ (negative lag) as $\mathrm{O}_{2}$ rise time increased (Figure 5E,F and Figure S4B). Maximal COA lags averaged $0.38 \pm 0.42 \mathrm{~s}$ and were associated with fast $\mathrm{O}_{2}$ rises, lasting 1.4-2.6 s (Figure 5F and G). Furthermore, the slope of COA vs. $\mathrm{O}_{2}$ amplitudes was time-scale dependent, peaking for $\mathrm{O}_{2}$ transients that took 2.3 to $6.2 \mathrm{~s}$ to rise (Figure 5E, G and Figure S4C) and progressively decreasing for longer $\mathrm{O}_{2}$ rises (Figure 5E, $\mathrm{H}$ and Figure $\mathrm{S} 4 \mathrm{C}$ ). The time-scale dependence of the COA vs. $\mathrm{O}_{2}$ slope is apparently related to the non-linear interaction between COA and $\mathrm{O}_{2}$, as a function of $\mathrm{O}_{2}$ rise time. Contrasting with the approximately linear increase in $\mathrm{O}_{2}$ 
1 amplitude as a function of $\mathrm{O}_{2}$ rise, the amplitude of corresponding COA peaks was, on average, nearly

2 time-scale independent for $\mathrm{O}_{2}$ rise times in the range of 3-14 s (Figure S4D).

3 In general, these results provide important insights into the interaction between COA and extracellular

$4 \quad \mathrm{O}_{2}$ in the hippocampus. The advancement of COA relative to $\mathrm{O}_{2}$ is apparently compatible with a Ch-

$5 \mathrm{O}_{2}$ directionality, possibly caused by ACh-evoked changes in local blood flow (Takata et al., 2013).

6 However, the diffusional delay underlying such a mechanism is expected to be constant as a function

7 of time-scale. Moreover, the time-scale dependence of the relative amplitude of enzyme response is

8 hard to interpret in light of a $\mathrm{Ch}-\mathrm{O}_{2}$ directionality. Alternatively, non-steady state $\mathrm{ChOx}$ responses to

$9 \mathrm{O}_{2}$ transients are fully compatible with our observations. Such modulation of sensor response is, by

10 definition, phasic and is expected to be amplified within an optimal, probably short, time-window.

11 Importantly, since phasic responses are short-lived, in addition to the time-scale dependence of

12 magnitude, this phenomenon predicts a continuous drift in $\mathrm{COA}-\mathrm{O}_{2}$ peak lags as $\mathrm{O}_{2}$ rise time

13 increases.

14 Together, these data converges to the hypothesis that the observed changes in COA are caused by $\mathrm{O}_{2}$

15 fluctuations. 

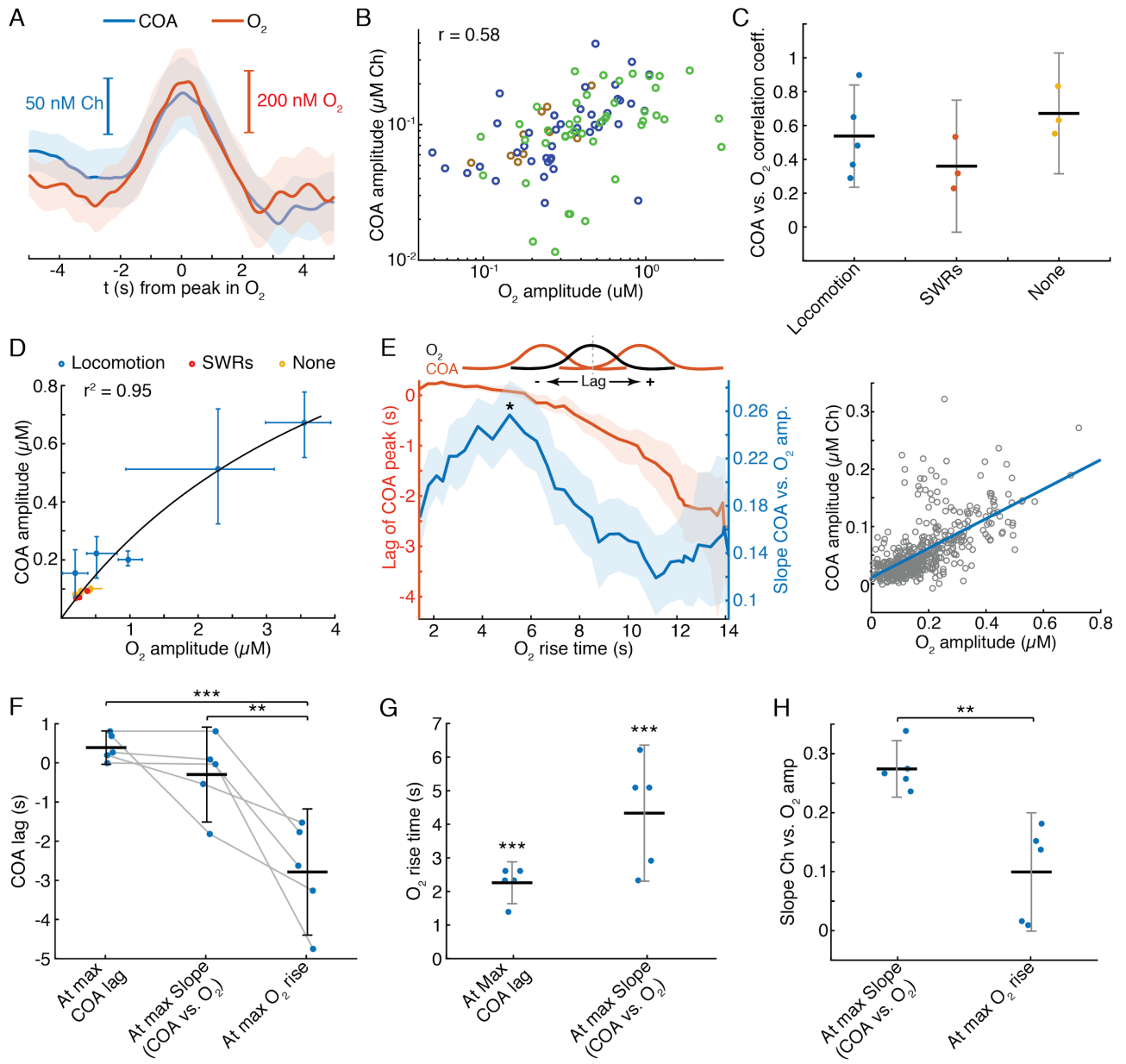

Figure 5. Correlation between $\mathrm{COA}$ and spontaneous $\mathrm{O}_{2}$ transients. (A) Average COA and $\mathrm{O}_{2}$ dynamics triggered to fast $\mathrm{O}_{2}$ transients (duration $\sim 5 \mathrm{~s}$ ) detected outside periods when SWRs or locomotion bouts occurred. Data is from one recording session ( $\mathrm{n}=42$ events). (B) Relationship between amplitudes of $\mathrm{O}_{2}$ and associated COA transients outside SWRs/locomotion bouts. Colors represent different recording sessions $(\mathrm{n}=10-$ 45 from 3 recordings, $\mathrm{r}_{\text {spearman }}=0.58, \mathrm{p}<0.001$ ). (C) Group summary of COA $v s . \mathrm{O}_{2}$ amplitude correlations under different behavioral and/or electrophysiological contexts. (D) COA vs. $\mathrm{O}_{2}$ amplitude across animals and states. Each point represents the median of events from a recording session. Data were fitted to the Michaelis-Menten equation, resulting in a $\mathrm{Vmax}=1.58$ and a $\mathrm{Km}=4.84$. (E) Lag of COA peaks relative to $\mathrm{O}_{2}$ peaks (red) and slope of COA vs. $\mathrm{O}_{2}$ amplitude (blue) for $\mathrm{O}_{2}$ transients with varying rise time for a single session; medians with CIs (left). Right shows the relationship between amplitudes of $\mathrm{O}_{2}$ and associated COA transients for the $\mathrm{O}_{2}$ rise time corresponding to largest slope marked with * on the left panel. (F) Group statistics on maximal COA lags, lags at maximal COA $/ \mathrm{O}_{2}$ slope and lags associated with longest $\mathrm{O}_{2}$ transients (ANOVA, $\mathrm{F}=15.22$, with posthoc Tukey test, $\mathrm{p}=0.51$ for max COA lag $v s$. lag at $\max \mathrm{COA} / \mathrm{O}_{2}$ ). (G) Group statistics on $\mathrm{O}_{2}$ rise times corresponding to maximal COA lags and $\mathrm{COA} / \mathrm{O} 2$ slope in (E). Values from both groups were significantly lower than the longest $\mathrm{O}_{2}$ rise time observed in a given recording $(\mathrm{p}<0.001$, one-sample $t$-test). (H) Group statistics on the slopes of COA vs. $\mathrm{O}_{2}$ amplitude at its maximum value and at maximum $\mathrm{O}_{2}$ rise. Differences between groups were significant $\left(\mathrm{p}<0.005\right.$, paired $t$-test). ${ }^{* *} \mathrm{p}<0.001, * * \mathrm{p}<0.01$. 


\section{Exogenous oxygen transients in the hippocampus elicit phasic COA responses}

2 Our correlational analysis points towards a possible effect of $\mathrm{O}_{2}$ transients on phasic sensor responses

3 in the hippocampus. We tested this hypothesis first by evoking changes in $\mathrm{O}_{2}$ by local application of small volumes of $\mathrm{O}_{2}$-saturated saline through a glass micropipette, positioned at a few hundred microns from the biosensor tip. To evoke different $\mathrm{O}_{2}$ profiles, we varied ejection parameters such as time and pressure.

7 Remarkably, immobilized ChOx exhibited robust phasic responses to exogenous $\mathrm{O}_{2}$ transients, 8 regardless of the time-scale of $\mathrm{O}_{2}$ change (Figure 6A and Figure S5A). Amplitudes of COA and $\mathrm{O}_{2}$

9 were significantly correlated $(\mathrm{p}<0.0001$, Figure $6 \mathrm{~B})$. However, similarly to spontaneous dynamics, the $\mathrm{CAO} / \mathrm{O}_{2}$ amplitude ratio of single events (equivalent to $\mathrm{CAO} / \mathrm{O}_{2}$ slope in spontaneous data) significantly decreased with $\mathrm{O}_{2}$ rise time in all experiments (negative correlation, $\mathrm{p}<0.05$, Figure $6 \mathrm{C}$ ). The decrease in COA amplitude was accompanied by the advancement of its peak relative to $\mathrm{O}_{2}$ $(p<0.001$ in all recordings, Figure 6D). Thus these results qualitatively recapitulate our observations for the spontaneous $\mathrm{COA}-\mathrm{O}_{2}$ interactions, reinforcing the putative $\mathrm{O}_{2}-\mathrm{COA}$ directionality. Next, we manipulated hippocampal $\mathrm{O}_{2}$ levels non-invasively, through inhalation, to further confirm $\mathrm{O}_{2}$ causality. We exposed mice to a pure $\mathrm{O}_{2}$ stream during variable periods (4-30 s) in order to generate different $\mathrm{O}_{2}$ transients. Like in the case of local $\mathrm{O}_{2}$ delivery, we observed reproducible changes in $\mathrm{COA}$ in response to exogenous $\mathrm{O}_{2}$ (Figure $6 \mathrm{E}$ and FigureS5B). The data showed a significant correlation between peak amplitudes ( $\mathrm{p}<0.0001$, Figure $6 \mathrm{~F})$. Importantly, both the $\mathrm{COA} / \mathrm{O}_{2}$ amplitude ratio and COA peak lag significantly decreased as a function of $\mathrm{O}_{2}$ rise time $(\mathrm{p}<0.05)$, corroborating the conclusions from local $\mathrm{O}_{2}$ manipulation.

Overall, $\mathrm{O}_{2}$ inhalation tended to generate slower and smaller $\mathrm{O}_{2}$ transients (and perhaps more physiological) than those by local application. Despite the differences in magnitudes and time-scales, the tested correlations are consistent across the two paradigms (Figure 6I) as well as with the spontaneous interactions between $\mathrm{COA}$ and $\mathrm{O}_{2}$ (Figure 5E-H). The results converge to the hypothesis that the putative cholinergic transients observed in the hippocampus of behaving rodents rather result from phasic modulation of COA by physiological $\mathrm{O}_{2}$ fluctuations. 
A

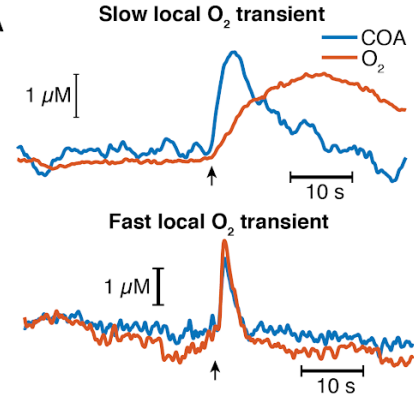

C

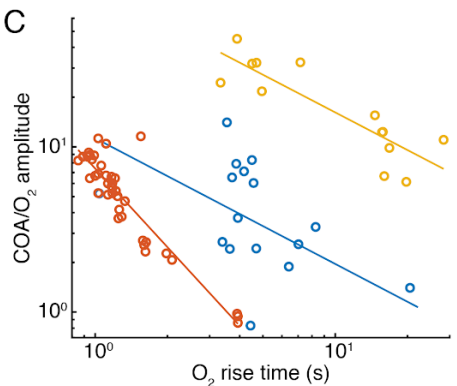

E Slow $\mathrm{O}_{2}$ transient by inhalation

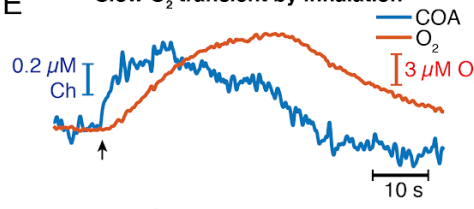

Fast $\mathrm{O}_{2}$ transient by inhalation

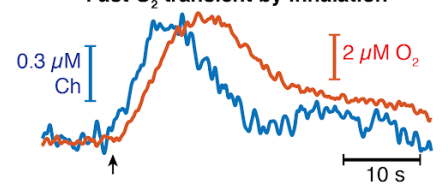

G

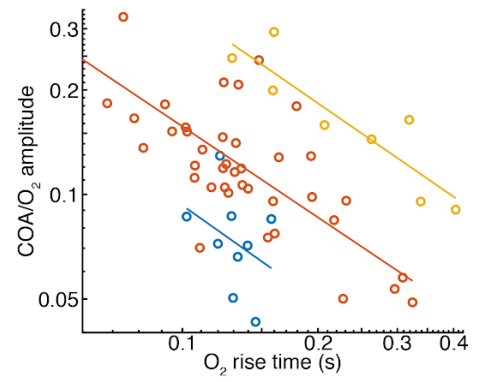

I

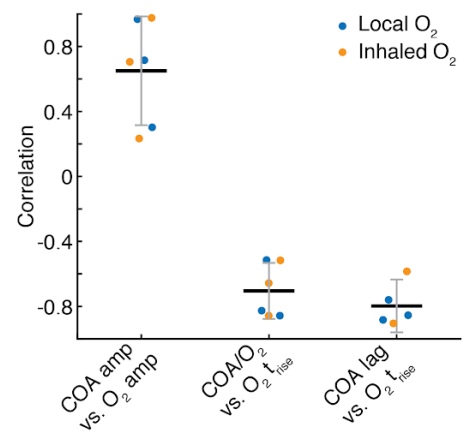

B
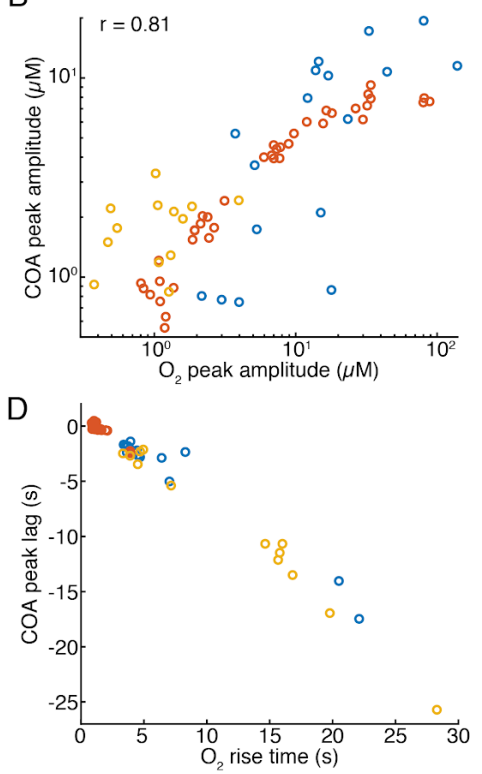

F

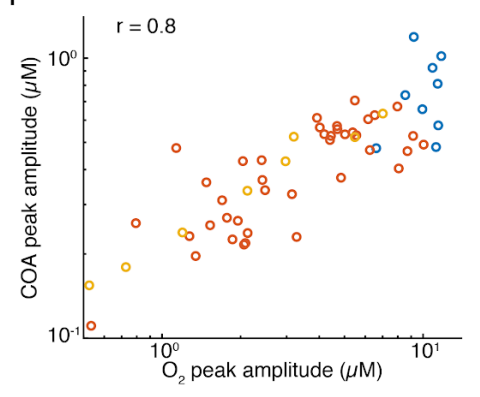

$\mathrm{H}$

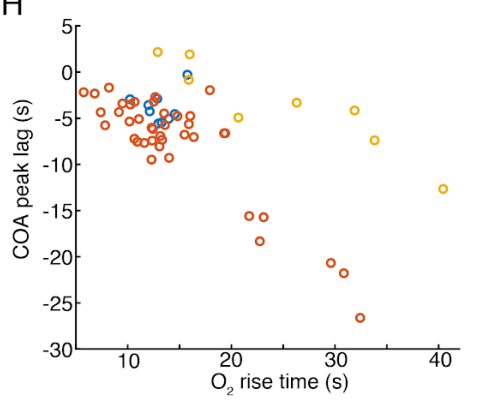

Figure 6. Exogeneous $\mathrm{O}_{2}$ elicits phasic $\mathrm{COA}$ responses in the hippocampus in vivo. (A) Representative examples of slow and fast $\mathrm{O}_{2}$ transients and associated $\mathrm{COA}$ responses evoked by local application of exogenous $\mathrm{O}_{2}$ from a glass micropipette. (B) Amplitudes of COA vs. locally-evoked $\mathrm{O}_{2}$ transients. Data were collected from three recording sessions (color-coded, $\mathrm{n}=13-40$ per session). Amplitudes were significantly correlated when pooling all data $\left(\mathrm{r}_{\text {spearman }}=0.81, \mathrm{p}<0.0001\right)$ and within 2 sessions $(\mathrm{p}<0.005$, in one session this 
analysis was not performed due to the narrow range of $\mathrm{O}_{2}$ amplitudes covered). (C) Ratio of COA vs. evoked $\mathrm{O}_{2}$ peak amplitudes as a function of $\mathrm{O}_{2}$ signal rise time. Colors denote recording sessions and trendlines are linear fits performed on data from each session. In all cases, the variables were negatively correlated ( $<<0.05)$. (D) Lag of COA relative to locally-evoked $\mathrm{O}_{2}$ transient peaks as a function of $\mathrm{O}_{2}$ rise time. Lags significantly decreased with $\mathrm{O}_{2}$ rise time in all sessions $\left(\mathrm{r}_{\text {spearman }}\right.$ for each recording ranged from -0.76 to $\left.-0.88, \mathrm{p}<0.001\right)$. (E) Representative traces showing slow and fast $\mathrm{O}_{2}$ transients and associated COA responses evoked by $\mathrm{O}_{2}$ inhalation. E-H plots are analogous to A-D, but for $\mathrm{O}_{2}$-inhalation-induced $\mathrm{O}_{2}$ transients. (F) Amplitudes of ChOx vs. $\mathrm{O}_{2}$ transients evoked by inhalation. Data were obtained from three recording sessions (color-coded, $\mathrm{n}=8-40$ per session). Variables were significantly correlated both when pooling the whole data $\left(\mathrm{r}_{\text {spearman }}=0.8\right.$, $\mathrm{p}<0.0001)$ and within individual experiments $(\mathrm{p}<0.0005)$. (G) Amplitude ratio of COA $v s$. inhalation-evoked $\mathrm{O}_{2}$ transients as a function of $\mathrm{O}_{2}$ signal rise time. Colors denote recording sessions and trendlines are linear fits performed on data from each session. The variables were significantly negatively correlated (red and yellow sessions, with $r_{\text {spearman }}$ coefficients of -0.66 and -0.86 respectively, $\mathrm{p}<0.05$ ). (H) Lags of COA relative to inhalation-evoked $\mathrm{O}_{2}$ peaks as a function of $\mathrm{O}_{2}$ rise time. Lags significantly decreased with $\mathrm{O}_{2}$ rise time (red and yellow sessions, $r_{\text {spearman }}$ of -0.58 and -0.90 respectively, $\left.\mathrm{p}<0.005\right)$. The analysis in $\mathrm{F}-\mathrm{H}$ was not performed within one session (blue dots) due to insufficient coverage of $\mathrm{O}_{2}$ amplitudes and rise times. (I) Summary of amplitude and $\mathrm{COA}-\mathrm{O}_{2}$ lags correlations for COA and $\mathrm{O}_{2}$ transients evoked by local $\mathrm{O}_{2}$ application and $\mathrm{O}_{2}$ inhalation. Data are presented as means \pm CIs. 


\section{Biosensor responses to oxygen have tonic and phasic components}

2 Given the in vivo causality between $\mathrm{O}_{2}$ and COA, we sought a detailed investigation of the biosensor

$3 \mathrm{O}_{2}$-dependence in vitro, in order to get mechanistic insights into the relationship between these signals. The in vitro tests were based on step additions of known $\mathrm{O}_{2}$ concentrations in the presence of a background $\mathrm{Ch}$ concentration $(5 \mu \mathrm{M})$ representative of average brain extracellular $\mathrm{Ch}$ tonic levels (Brehm et al., 1987; Garguilo and Michael, 1996; Parikh et al., 2004). Unlike previous studies, this allowed us to get a clear distinction between phasic vs. steady-state (tonic) sensor responses.

Notably, upon removal of $\mathrm{O}_{2}$ from solution and in the presence of background $\mathrm{Ch}$, most biosensors responded to consecutive $\mathrm{O}_{2}$ steps with a fast transient (phasic component) before reaching a steadystate (Figure 7A). Both phasic and tonic components decreased with $\mathrm{O}_{2}$ baseline, but not equally. The phasic response was usually still prominent upon the exhaustion of the tonic component (Figure 7A). We quantified these differences by fitting the Michaelis-Menten equation to the tonic changes and the Hill equation to the cumulative phasic peaks, as the latter did not appear to follow a pure MichaelisMenten profile (Figure 7B). The resulting phasic $\mathrm{K}_{0.5} \mathrm{O}_{2}$ values for phasic responses were, on average, one order of magnitude larger than tonic $\mathrm{KmO}_{2}$, reinforcing that the phasic component vanishes at much larger $\mathrm{O}_{2}$ baselines than tonic responses ( $\mathrm{p}<0.0005$, Figure $7 \mathrm{C}$ ). Importantly, the phasic $\mathrm{ChOx}$ response was not matched by a fast $\mathrm{O}_{2}$ transient following each addition, as $\mathrm{O}_{2}$ raised considerably slower than the peak in COA (Figure 7D).

Next, we assessed how the coating composition and its physical properties could modulate the sensor $\mathrm{O}_{2}$-dependence. First, we calculated the biosensor efficiency (ratio of Choline vs. $\mathrm{H}_{2} \mathrm{O}_{2}$ sensitivities), as a proxy to the enzyme loading in the coating and plotted it against tonic $\mathrm{KmO}_{2}{ }^{\text {app }}$ (Figure 7E). The result revealed a decreasing trend (Figure 7E), suggesting that biosensors with a high enzyme loading have low sensitivity to tonic $\mathrm{O}_{2}$ changes (low- $\mathrm{KmO}_{2}{ }^{\text {app }}$ ). Strikingly, the biosensors with the lowest tonic $\mathrm{KmO}_{2}{ }^{\text {app }}$ exhibited the highest phasic peaks (Figure $7 \mathrm{~F}$ ), with maximal phasic responses to $\mathrm{O}_{2}$ decreasing exponentially as a function of $\mathrm{KmO}_{2}{ }^{\text {app }}$ (Figure $7 \mathrm{G}$ ).

In order to further detail on the effect of $\mathrm{O}_{2}$ baseline on non-stationary COA, we split the sensor calibrations into two groups according to their tonic $\mathrm{O}_{2}$-dependence. As already suggested in Figure $7 \mathrm{D}$, we confirmed that the larger phasic responses in the low- $\mathrm{KmO}_{2}{ }^{\text {app }}$ vs. high- $\mathrm{KmO}_{2}{ }^{\text {app }}$ groups could not be attributed to differences in the underlying $\mathrm{O}_{2}$ profiles. Oxygen transients after each addition were negligible and did not significantly differ across $\mathrm{KmO}_{2}{ }^{\text {app }}$ groups $(\mathrm{p}=0.998$, Figure $7 \mathrm{H})$. Noteworthy, in the low- $\mathrm{KmO}_{2}{ }^{\text {app }}$ group, the highest COA peak was achieved in response to the second $\mathrm{O}_{2}$ addition $\left(10 \mu \mathrm{M}\right.$ of cumulative $\left.\left[\mathrm{O}_{2}\right]\right)$ rather than to the first in 6 out of 7 calibrations (marginally significant difference between 5 and $10 \mu \mathrm{M} \mathrm{O}_{2}$ responses, $\mathrm{p}=0.076$, paired $t$-test). Furthermore, the same COA peaks had the longest decay across the two $\mathrm{KmO}_{2}{ }^{\text {app }}$ groups $(\mathrm{p}<0.0005$, Figure $7 \mathrm{I})$. These non-monotonic profiles with respect to $\left[\mathrm{O}_{2}\right]$ reflected the deviation of the cumulative phasic COA vs. $\mathrm{O}_{2}$ curves from a Michaelis-Menten kinetics. Accordingly, the Hill coefficients extracted from 
1 calibration fittings (e. g. Figure 7B) were above 2 for sensors with low $\mathrm{KmO}_{2}{ }^{\text {app }}$ and significantly

2 decreased towards 1 as $\mathrm{KmO}_{2}{ }^{\text {app }}$ increased $(\mathrm{p}<0.05)$. These observations suggest a cooperative

3 mechanism that enhances phasic responses as the $\mathrm{O}_{2}$ baseline increases, in biosensors with low tonic

$4 \quad \mathrm{O}_{2}$ dependence.

5 In summary, we show that, under a Ch background, ChOx biosensors respond to $\mathrm{O}_{2}$ with a transient

6 increase in enzyme activity before reaching a steady-state. Importantly, phasic and tonic components

7 were apparently mutually exclusive and their relative magnitude was sensitive to the properties of the

8 enzyme coating, namely enzyme loading. Sensors with high enzyme loading have a low tonic $\mathrm{O}_{2-}$

9 dependence and show large phasic responses that seem to be potentiated by the $\mathrm{O}_{2}$ baseline.

10 A possible explanation for the sensors' phasic and tonic components and their anti-correlation is the

11 local consumption of $\mathrm{Ch}$ within the coating milieu, boosted by phasic $\mathrm{O}_{2}$. In that case, a large $\mathrm{Ch}$

12 depletion, in sensors with high enzyme loading, would blunt the tonic ChOx response to $\mathrm{O}_{2}$ while

13 sparing the initial non-steady-state peak in enzyme activity. 

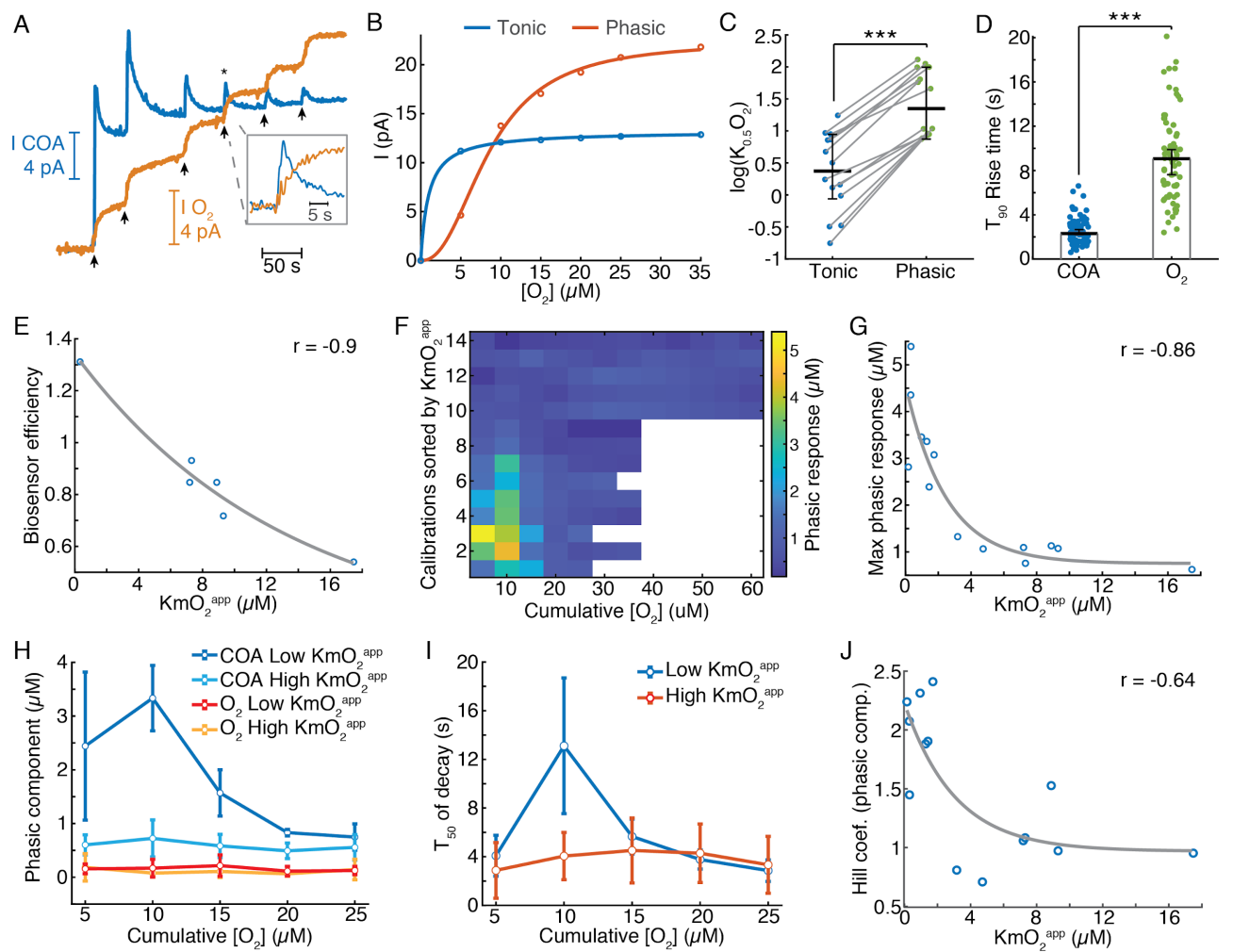

Figure 7. Biosensors generate tonic and phasic $\mathrm{COA}$ components in response to $\mathrm{O}_{2}$. (A) An example of an in vitro $\mathrm{O}_{2}$ calibration. Upon removal of $\mathrm{O}_{2}$ from PBS containing $5 \mu \mathrm{M} \mathrm{Ch}$, step additions of $5 \mu \mathrm{M} \mathrm{O}_{2}$ (arrows) were performed until the tonic sensor response saturated. (B) Representative cumulative function of tonic and phasic responses as a function of $\mathrm{O}_{2}$ baseline after each addition. Tonic data were fitted with the MichaelisMenten equation, resulting in a $\mathrm{KmO}_{2}{ }^{\text {app }}$ of $0.97 \mu \mathrm{M}(\mathrm{CI}=0.818-1.126 \mu \mathrm{M})$ and $\mathrm{I}_{\max }=13.2 \mathrm{pA}(\mathrm{CI}=13.04-$ $13.37 \mathrm{pA}$ ), with RMSE $=0.08 \mathrm{pA}$. Phasic responses were fitted to the Hill equation, yielding $\mathrm{K}_{0.5} \mathrm{O}_{2}=8.6 \mu \mathrm{M}$ $(\mathrm{CI}=7.58-9.62 \mu \mathrm{M})$, Hill coefficient $n=2.31(\mathrm{CI}=1.74-2.88)$ and $\mathrm{I}_{\max }=22.4 \mathrm{pA}(\mathrm{CI}=20.6-24.1)$, with rmse $=0.50 \mathrm{pA}$. (C) $\mathrm{K}_{0.5} \mathrm{O}_{2}{ }^{\text {app }}$ values of tonic and phasic components from all biosensors ( $\left.\mathrm{n}=14\right)$. Averages and error bars are medians and 95\% CIs. The two groups were significantly different (sign test, $p<0.0005$ ). (D) $T_{90}$ rise times of $\mathrm{O}_{2}$ steps and COA peaks following $\mathrm{O}_{2}$ additions $(\mathrm{n}=72-95)$. Bars and error bars represent medians and $95 \%$ CIs, two samples were significantly different ( $<<0.0001$, Wilcoxon rank sum test). (E) Biosensor efficiency $\left(\mathrm{Ch} / \mathrm{H}_{2} \mathrm{O}_{2}\right.$ sensitivity ratio) as a function of $\mathrm{KmO}_{2}{ }^{\text {app }}(\mathrm{n}=6)$. For illustrative purposes, data were fitted with an exponential function. Spearman correlation between variables was $-0.9(p=0.028)$. (F) Amplitude of phasic response (color) as a function of cumulative $\mathrm{O}_{2}$ after each addition, sorted by sensor's tonic $\mathrm{KmO}_{2}{ }^{\text {app }}$. Amplitudes were calculated as $\mathrm{Ch}$ concentration, based on sensors' response to $5 \mu \mathrm{M} \mathrm{Ch}$. (G) Maximal response to $\mathrm{O}_{2}$ (from each biosensor calibration) as a function of $\mathrm{KmO}_{2}{ }^{\text {app }}(\mathrm{n}=14)$. The negative correlation between the variables was significant $\left(\mathrm{r}_{\text {spearman }}=-0.86, \mathrm{p}<0.0001\right)$. Data were fitted with an exponential decay curve (fitted decay constant $k=0.4 \mu \mathrm{M}^{-1}\left(\mathrm{CI}=0.031-0.78 \mu \mathrm{M}^{-1}\right.$, rmse $\left.=0.68 \mu \mathrm{M}\right)$. $(\mathrm{H})$ Amplitudes of phasic ChOx responses divided into low and high- $\mathrm{KmO}_{2}{ }^{\text {app }}$ groups ( $\mathrm{n}=7$ in each group) following consecutive step additions of $\mathrm{O}_{2}$. Control phasic $\mathrm{O}_{2}$ values obtained using the same algorithm are also plotted for the same groups ( $\mathrm{n}=6$ for high$\mathrm{KmO}_{2}{ }^{\text {app }}$ and $\mathrm{n}=4$ for high- $\mathrm{KmO}_{2}{ }^{\text {app }}$ ). Low- $\mathrm{KmO}_{2}{ }^{\text {app }}$ transients were significantly higher than those from the high- $\mathrm{KmO}_{2}{ }^{\text {app }}$ group $(\mathrm{p}<0.0001)$ and the amplitudes from both ChOx groups were significantly higher than any $\mathrm{O}_{2}$ group $(\mathrm{p}<0.005)$. Oxygen transients from low $-\mathrm{KmO}_{2}{ }^{\text {app }}$ vs. high $-\mathrm{KmO}_{2}{ }^{\text {app }}$ groups did not significantly differ $(\mathrm{p}=0.998)$. Group comparisons done by two-way ANOVA for unbalanced data followed by Tukey-Kramer posthoc tests. (I) $\mathrm{T}_{50}$ decay time of transients from low- and high- $\mathrm{KmO}_{2}{ }^{\text {app }}$ groups as a function of cumulative $\mathrm{O}_{2}$. The decay of peaks in response to $10 \mu \mathrm{M}$ cumulative $\left[\mathrm{O}_{2}\right]$ was significantly longer than any other condition $(\mathrm{p}<0.0005$, two-way ANOVA for unbalanced data followed by Tukey-Kramer post-hoc tests). (J) Hill coefficient from the fits of cumulative COA phasic component vs. cumulative $\mathrm{O}_{2}$ (as in $\mathrm{B}$ ) as a function of $\mathrm{KmO}_{2}^{\text {app }}(\mathrm{n}=14)$. The two variables were negatively correlated $\left(\mathrm{r}_{\text {spearman }}=-0.64, \mathrm{p}=0.015\right)$, showing an exponential-like relationship (fitted initial amplitude of $1.27 \pm 0.75$, decay constant of $0.33 \pm 0.62 \mu \mathrm{M}^{-1}$ and 
bioRxiv preprint doi: https://doi.org/10.1101/2020.08.05.237453; this version posted Auqust 6.2020 . The copyriaht holder for this preprint (which was not certified by peer review) is the author/funder, who has granted bioRxiv a license to display the preprint in perpetuity. It is made available under aCC-BY 4.0 International license.

offset of $0.97 \pm 0.67) .{ }^{* * *} \mathrm{p}<0.001$.

2 

and phasic oxygen-dependence

3 In order to provide a theoretical ground for our in vitro observations, we have simulated the behavior 4 of biosensors in calibration conditions. We numerically solved a system of partial differential equations describing the diffusion of $\mathrm{Ch}$ and $\mathrm{O}_{2}$ in the coating and their interaction with the enzyme, leading to $\mathrm{H}_{2} \mathrm{O}_{2}$ generation.

7 To mimic our experimental calibrations, we simulated sensor responses to $5 \mu \mathrm{M}$ step increases in $\mathrm{O}_{2}$

8 (starting from zero) under a constant level of $5 \mu \mathrm{M} \mathrm{Ch}$ in the bulk solution. Remarkably, in line with our experimental findings, the model predicted phasic and tonic components of sensor response to $\mathrm{O}_{2}$ whose magnitude depended on $\mathrm{O}_{2}$ baseline (Figure 8A). Sensors with high enzyme loading showed higher phasic peaks and tonic responses that saturate at lower $\mathrm{O}_{2}$ baselines than sensors with a low enzyme amount (Figure 8A). To get a more resolved characterization of biosensor's $\mathrm{O}_{2}$ dependence, we next generated response curves at $1 \mu \mathrm{M} \mathrm{O}_{2}$ steps, until saturation of enzymatic $\mathrm{H}_{2} \mathrm{O}_{2}$ generation was nearly reached (see Methods). By simulating a range of coating thicknesses and enzyme concentrations, we found that both parameters decreased $\mathrm{KmO}_{2}{ }^{\text {app }}$ of tonic responses (Figure 8B) and increased the magnitude of phasic peaks (Figure 8C). Interestingly, our model predicts that particular combinations of coating thickness and enzyme concentration can be used to optimize sensor sensitivity to $\mathrm{Ch}$ (at saturating $\mathrm{O}_{2}$ levels) (Figure S6A). Yet, such a strategy is not expected to concomitantly reduce phasic and tonic $\mathrm{O}_{2}$ dependence, which seem to be mutually exclusive. In agreement with the experimental data, our model anticipated that sensors with the lowest $\mathrm{KmO}_{2}{ }^{\text {app }}$ exhibit the highest transient responses to $\mathrm{O}_{2}$ (Figure 8B-D). Across the simulated coatings, the highest phasic peaks occurred when sensor cumulative tonic responses were close to maximal and progressively decreased in sensor tonic saturation level as a function of tonic $\mathrm{KmO}_{2}{ }^{\text {app }}$ (Figure $8 \mathrm{D}$ ). This observation is in agreement with our experimental observation of highest phasic peaks at a 10 $\mu \mathrm{M} \mathrm{O}_{2}$ baseline (Figure $7 \mathrm{H}-\mathrm{J}$ ).

To get further clues into the factors shaping sensors' $\mathrm{O}_{2}$-evoked responses, we analyzed the concentration dynamics of $\mathrm{Ch}$ and $\mathrm{O}_{2}$ in the coatings during simulated calibrations. We observed that, under high enzyme loading, $\mathrm{Ch}$ is rapidly depleted in the coating as $\mathrm{O}_{2}$ levels in solution increase (Figure 8E). This effect is less pronounced in sensors with low enzyme loading (Figure 8F). Interestingly, significant $\mathrm{O}_{2}$ consumption, observed mainly in coatings highly loaded with enzyme, was stronger for low $\mathrm{O}_{2}$ levels before reaching saturation of the sensor tonic response (Figure 8G). These observations suggest that depletion of $\mathrm{Ch}$ in the enzyme coating is the limiting factor that shapes sensors' tonic responses to $\mathrm{O}_{2}$.

To further investigate phasic responses under high enzyme loading, in addition to substrate profiles, we assessed the levels enzyme-bound reduced intermediate species vs. buffer $\mathrm{O}_{2}$ concentration, as those are direct precursors of $\mathrm{H}_{2} \mathrm{O}_{2}$. We observed that, under non-saturating $\mathrm{O}_{2}$ levels, the 
1 concentrations of $\mathrm{E}_{\mathrm{red}} \mathrm{BA}$ and $\mathrm{E}_{\mathrm{red}} \mathrm{GB}$ change oppositely as $\mathrm{O}_{2}$ is increased, which maintains the sum

2 of both intermediates relatively stable (Figure S6B). At $1 \mu \mathrm{M}$ buffer $\mathrm{O}_{2}$ steps, the profiles of reduced

3 intermediates, $\mathrm{Ch}$ and $\mathrm{O}_{2}$ at the electrode surface, suggest that phasic biosensor peaks result from a

4 combination of multiple factors (Figure 8H). As expected, the sensor's tonic response steeply decays

5 upon Ch depletion in the coating. This decrease is accompanied by a sharp rise in the instantaneous

$6 \Delta \mathrm{O}_{2}$ at the electrode surface evoked by $\mathrm{O}_{2}$ increments in the bulk solution. As the rate of $\mathrm{O}_{2}$

7 consumption depends on the concentration of reduced enzyme-bound complexes, the increasing

8 profile of $\Delta \mathrm{O}_{2}$ results, in a first stage, from the depletion of the $\mathrm{E}_{\text {red }} \mathrm{BA}$ complex, followed by the

9 decrease in $\mathrm{E}_{\text {red }} \mathrm{GB}$ (Figure $\mathrm{S6B}$ ). In turn, the amount of $\mathrm{E}_{\mathrm{red}} \mathrm{BA}$ and $\mathrm{E}_{\text {red }} \mathrm{GB}$ depends on both $\mathrm{Ch}$ and

$10 \mathrm{O}_{2}$, which leads to a summed profile that is shifted to the right relative to the sensor's tonic response.

11 Thus, phasic sensor peaks reach maximal levels at the offset of tonic responses, when there is a

12 combination of relatively large concentrations of the direct $\mathrm{H}_{2} \mathrm{O}_{2}$ precursors, namely enzyme-bound

13 reduced complexes and $\mathrm{O}_{2}$, and very low levels of $\mathrm{Ch}$ in the coating (Figure $8 \mathrm{H}$ ).

14 Overall, our biosensor simulations corroborate the in vitro results, firstly converging towards the 15 notion that $\mathrm{Ch}$ consumption in the coating is a major factor governing sensor tonic $\mathrm{O}_{2}$ dependence.

16 Secondly, the results suggest that non-steady state phasic responses depend on the relative concentrations of $\mathrm{Ch}$, reduced intermediate enzyme complexes and $\mathrm{O}_{2}$ in the coating. 

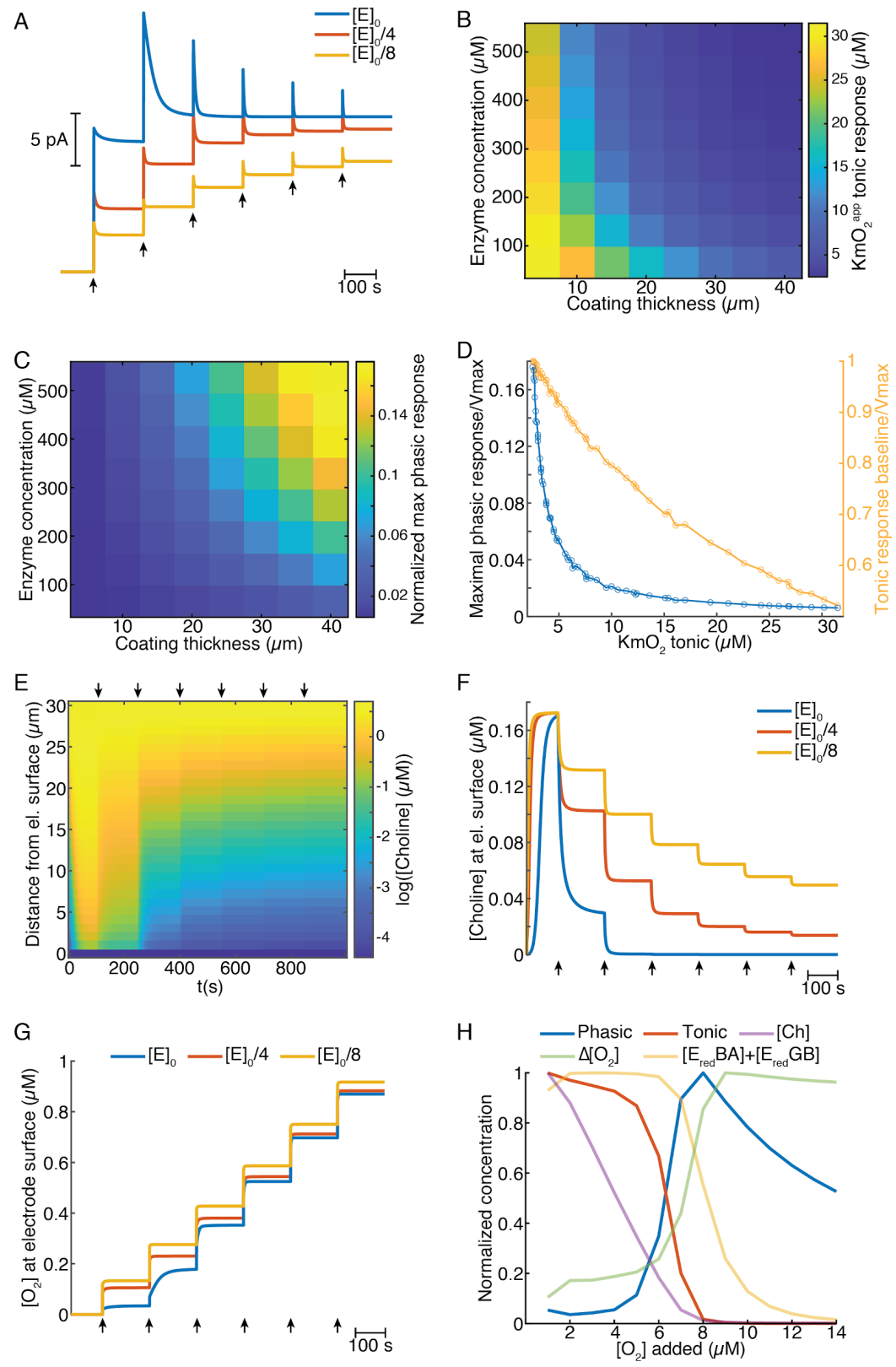

Figure 8. Mathematical model explains ChOx-based biosensor COA responses to oxygen. (A) Simulated calibrations of biosensors with different enzyme concentrations in the coating (coating thickness of $30 \mu \mathrm{m}$ ). Choline in bulk solution was kept constant at $5 \mu \mathrm{M}$ and $\mathrm{O}_{2}$ was incremented in $5 \mu \mathrm{M}$ steps from zero to $30 \mu \mathrm{M}$ at times indicated by arrows. (B) Apparent $\mathrm{KmO}_{2}$ of tonic sensor responses as a function of coating thickness and enzyme concentration in the coating. (C) Normalized maximal phasic responses of sensors with different coating thicknesses and enzyme concentrations. Phasic component magnitudes for each sensor refer to the highest phasic response divided by the maximal cumulative tonic response (Imax) from the respective simulated sensor calibration. (D) Blue trace represents the normalized maximal phasic response vs. tonic $\mathrm{KmO}_{2}{ }^{\text {app }}$ and the orange trace refers to the level of saturation of the sensor's tonic response at which the maximal phasic peak occurs. Data were obtained from all combinations of coating thickness and enzyme concentration in $\mathrm{B}$ and $\mathrm{C}$. (E) Concentration profile of $\mathrm{Ch}$ in the sensor coating as a function of distance from the electrode surface during a simulated calibration of a high enzyme-loaded sensor (coating thickness of $30 \mu \mathrm{m}$ and enzyme concentration of $560 \mu \mathrm{M}$, same as the blue trace in A). Arrows indicate $5 \mu \mathrm{M} \mathrm{O}_{2}$ step increments in solution. (F) Time-course of $\mathrm{Ch}$ concentration at the electrode surface of sensors with different enzyme concentrations during simulated calibrations. Arrows indicate $5 \mu \mathrm{M} \mathrm{O}_{2}$ step increments in solution. (G) Timecourse of $\mathrm{O}_{2}$ concentration at the electrode surface for sensors with different enzyme concentrations during simulated calibrations. Arrows indicate $5 \mu \mathrm{M} \mathrm{O}_{2}$ step increments in solution. $(\mathrm{H})$ Normalized profiles of phasic 

made available under aCC-BY 4.0 International license.

1 and tonic sensor responses as well as of concentrations of enzyme substrates and total reduced enzyme-bound 2 complexes at the electrode surface as a function of $\mathrm{O}_{2}$ in solution. Data are from a simulated calibration of a 3 sensor with a $30 \mu \mathrm{m}$ coating and an enzyme concentration of $560 \mu \mathrm{M}$, upon $1 \mu \mathrm{M} \mathrm{O}_{2}$ step increases in solution. 4 The $\Delta \mathrm{O}_{2}$ is the initial rise in $\mathrm{O}_{2}$ following each $\mathrm{O}_{2}$ increment in solution (at a lag of $0.3 \mathrm{~s}$ ). 


\section{Discussion}

2 We have developed a novel multi-site tetrode-based amperometric ChOx (TACO) sensor optimized

3 for the highly sensitive and unbiased simultaneous measurement of putative cholinergic activity and

$4 \mathrm{O}_{2}$ dynamics in the brain. Our approach, based on the differential plating of recording sites to create

5 pseudo-sentinel channels outperforms previous common-mode rejection strategies, which were

6 limited by diffusional cross-talk (Burmeister et al., 2003; Parikh et al., 2007; Santos et al., 2015). This

7 strategy allowed us to substantially reduce the size and increase the spatial confinement of recording

8 sites by using a $17 \mu \mathrm{m}$ wire tetrode as the biosensor electrode support. Our recordings in freely-

9 moving and head-fixed rodents reveal the usefulness of this compact multi-site design to clean artifacts from sensor signals and assess the correlation between the activity of the immobilized enzyme and brain extracellular $\mathrm{O}_{2}$ on a fast time-scale. Importantly, this method can be generalized to improve the selectivity and address the in vivo $\mathrm{O}_{2}$-dependence of any oxidase-based biosensor. By simultaneously measuring the activity of immobilized $\mathrm{ChOx}$ and extracellular $\mathrm{O}_{2}$ in the hippocampus of behaving mice, we found that fast biosensor signals correlate in amplitude and time with $\mathrm{O}_{2}$ transients evoked by behavioral and network dynamics events exemplified by locomotion bouts and SWRs. Notably, the relationship between $\mathrm{COA}$ and $\mathrm{O}_{2}$ profiles was apparently not sensitive to the underlying neurophysiological or behavioral context and was preserved during periods without appreciable SWR incidence or locomotion. By using two different methods to manipulate extracellular $\mathrm{O}_{2}$, we show that $\mathrm{O}_{2}$ fluctuations in the physiological range can drive phasic COA. Remarkably, the time-scale dependence of biosensor response amplitude and lag relative to exogenous $\mathrm{O}_{2}$ qualitatively matched that of spontaneous profiles, suggesting that the same directionality happens in spontaneous conditions. Locomotion-related $\mathrm{O}_{2}$ elevations in head-fixed mice have been recently shown to be modulated mainly by respiration rate (Zhang et al., 2019), whereas SWR-evoked $\mathrm{O}_{2}$ peaks have been indirectly inferred by fMRI and likely result from neurovascular coupling (Ramirez-Villegas et al., 2015). Thus our study provides a link between the neurophysiological or systemic mechanisms that modulate brain $\mathrm{O}_{2}$ levels and the response of ChOx-based biosensors in vivo. As it is an intrinsic component of any behavioral task, our results highlight the importance of controlling for $\mathrm{O}_{2}$-evoked biosensor signals related to locomotion or movement. It is thus likely that, in reward-related tasks, locomotion related to reward retrieval elicits few seconds delayed phasic changes in $\mathrm{O}_{2}$ that drive transient increases in COA. Likewise, a high incidence of SWRs in reward locations, reflecting a consummatory state (Buzsáki, 2015), might trigger $\mathrm{O}_{2}$ transients and, in turn, phasic ChOx biosensor responses. These two examples provide alternative explanations for previously reported cholinergic transients inferred from COA signals in the prefrontal cortex and hippocampus of rodents engaged in cognitive tasks (Howe et enzymatic reaction depends on both substrates, biosensor responses caused by $\mathrm{O}_{2}$ transients are 
expected to decrease following experimental controls that have been aimed at inhibiting or removing cholinergic inputs (Parikh et al., 2007).

Our in vitro characterization of the biosensor $\mathrm{O}_{2}$ dependence provided critical insights to interpret the in vivo relationship between $\mathrm{COA}$ and $\mathrm{O}_{2}$. We found robust $\mathrm{O}_{2}$-evoked phasic responses whose amplitude was anti-correlated with sensors' tonic $\mathrm{O}_{2}$ dependence. Interestingly the phasic peaks decreased with $\mathrm{O}_{2}$ baseline but were detected even under relatively high $\mathrm{O}_{2}$ levels, suggesting a high likelihood of such responses to occur in vivo. Thus, our data emphasize the impact of $\mathrm{O}_{2}$-evoked nonsteady-state biosensor dynamics on fast time-scale in vivo measurements. This has not been described in previous studies partly because the experimental procedures used to study $\mathrm{O}_{2}$-dependence were unable to unmix tonic and phasic components of sensor response (Baker et al., 2017; Burmeister et al., 2003; Dixon et al., 2002). Instead of generating a continuous $\mathrm{O}_{2}$ increase, we induced step increments in $\mathrm{O}_{2}$, allowing temporal deconvolution of sensor response components and unbiased estimation of the corresponding $\mathrm{K}_{0.5} \mathrm{O}_{2}{ }^{\text {app }}$ values.

Remarkably, most of our observations related to sensor $\mathrm{O}_{2}$-dependence were predicted by mathematical simulation of biosensor responses in vitro. The model incorporated the kinetics of the enzyme-catalyzed reaction, including enzyme-bound intermediate species, and simulated substrates' diffusion into the coating and interaction with the enzyme leading to $\mathrm{H}_{2} \mathrm{O}_{2}$ formation. In agreement with the experimental data, the model predicted that tonic and phasic components of $\mathrm{O}_{2}$ dependence are mutually exclusive. Furthermore, our simulations suggest that increasing the enzyme loading, either by changing enzyme concentration or the coating thickness, amplifies sensor phasic responses and reduces tonic $\mathrm{KmO}_{2}{ }^{\text {app }}$. It is therefore apparent that there is no perfect combination of these two parameters that can concomitantly minimize the two components of biosensor $\mathrm{O}_{2}$ dependence. In addition to reinforcing our experimental conclusions, the biosensor model provided important insights into the factors that determine phasic and tonic components of $\mathrm{O}_{2}$ dependence. Simulated profiles showed that tonic responses to $\mathrm{O}_{2}$ are largely shaped by $\mathrm{Ch}$ depletion in the coating, which limits the linearity of the sensor response. On the other hand, phasic responses depended on the instantaneous balance between the concentration of substrates and reduced enzyme-bound intermediates, which lead to the formation of $\mathrm{H}_{2} \mathrm{O}_{2}$. Simulated transients were highest when the concentration of reduced intermediates and $\mathrm{O}_{2}$ were in relative excess in comparison to $\mathrm{Ch}$. Since variations in enzyme concentrations, coating thickness and diffusional components have mainly a quantitative effect in our estimates, these conclusions can be extrapolated to sensor geometries and enzyme coating compositions that we have not covered. Furthermore, mathematical model of the biosensor described here provides a rigorous approach for exploration and optimization of the design of any future enzymatic biosensors and investigation of their behavior under non-stationary in vivo conditions.

The phasic $\mathrm{O}_{2}$-evoked COA signals described in vitro and predicted by mathematical modeling provide crucial information to interpret the time-scale dependence of in vivo sensor dynamics triggered either to spontaneous or exogenously evoked $\mathrm{O}_{2}$ peaks. In light of those results, the temporal 
advancement and amplitude drop of biosensor transients relative to $\mathrm{O}_{2}$, as $\mathrm{O}_{2}$ rises for longer periods, is compatible with a major contribution of the phasic component of biosensor's $\mathrm{O}_{2}$-dependence. This observation suggests that, in vivo, our biosensors operated in a regime close to saturation of the tonic response and highlight the effect of non-steady-state $\mathrm{ChOx}$ biosensor responses to $\mathrm{O}_{2}$, which can be erroneously attributed to $\mathrm{Ch}$.

Our observations disfavor the quantitative optimization of coating properties as a strategy to reduce sensors' $\mathrm{O}_{2}$ dependence. Instead, we anticipate that strategies that increase $\mathrm{O}_{2}$ accumulation in the enzyme coating (Njagi et al., 2008) might have relative success, although the high $\mathrm{O}_{2}$ levels required to cancel phasic responses are hard to reach passively. Alternatively, some oxidase-based biosensors for in vitro applications have incorporated an electrochemical actuator that enables local manipulation of $\mathrm{O}_{2}$ concentration based on water electrolysis (Park et al., 2006). However, applying such design in vivo would require miniaturization and separation between the $\mathrm{O}_{2}$ generation compartment and the brain to avoid electrolytic tissue damage. Furthermore, in addition to the main $\mathrm{O}_{2}$ confound, one cannot completely rule out a possible modulation of $\mathrm{COA}$ in vivo by factors that affect enzyme conformation, including temperature and $\mathrm{pH}$ (Hekmat et al., 2008). Although the enzyme is poorly sensitive to the modest variations of these factors in vivo (Csernai et al., 2019; Venton et al., 2003), it would be relevant to characterize their potential contribution to COA dynamics in future studies. A further validation of ChOx-based measurements could be achieved by confronting the dynamics of COA with that of cholinergic signals measured with other sensing approaches, under the same experimental conditions. The latter technics include optogenetically-taged single unit recordings or fluorescence reporters, which have previously revealed fast cholinergic dynamics related to arousal, sensory sampling, negative reinforcements and unexpected events (Eggermann et al., 2014; Hangya et al., 2015; Lovett-Barron et al., 2014; Reimer et al., 2016).

In summary, our results suggest that $\mathrm{ChOx}$ biosensor signals in vivo are composed of a mixture of $\mathrm{O}_{2}$ related artifacts and true cholinergic dynamics. The weight of each factor depends on the time-scale, with slow state-related changes reflecting cholinergic dynamics with low $\mathrm{O}_{2}$-related contamination and fast transients, except for a minor fraction (less than ca. 5\% in our data), being caused by phasic $\mathrm{O}_{2}$ fluctuations. We show that $\mathrm{O}_{2}$ transients can be triggered by cognitively-relevant events, such as locomotion and periods of high SWR incidence, and confound the ChOx-based measurement of cholinergic activity. Thus, our study reveals a previously ignored phasic $\mathrm{O}_{2}$-dependence of $\mathrm{ChOx}-$ based biosensors which is critical to control for, particularly in the case of fine time-scale measurements of ACh.

Importantly, our conclusions can probably be generalized to other oxidase-based biosensors that have been used to measure neurotransmitters or metabolically-relevant molecules in the brain (Chatard et al., 2018; Dixon et al., 2002; Hascup et al., 2013; McMahon et al., 2007). The exact extent of phasic and tonic $\mathrm{O}_{2}$ dependence would depend on the particular enzyme kinetics and on the basal extracellular concentrations of analyte relative to the magnitude of changes in the brain. 


\section{Materials and Methods}

\section{Chemicals and solutions}

3 All chemicals were of analytical grade, purchased from Sigma-Aldrich and used as received.

4 Solutions were prepared in ultra-pure deionized water $(\geq 18 \mathrm{M} \Omega . \mathrm{cm})$ from a Milli-Q water purification

5 system.

\section{$6 \quad$ Tetrode fabrication and platings}

7 The microelectrode support material was a $17 \mu \mathrm{m}$ diameter Platinum/Iridium (90/10) wire insulated 8 by a polyimide coating (California Fine Wire Company). Tetrodes were fabricated using standard 9 methods (Gray et al., 1995). Briefly, four wires were twisted together and heated to melt the insulation, creating a stiff bundle of twisted wires. The wires' insulation at the untwisted ending of the tetrode was then removed and the tetrode was inserted in a silica tube (150 $\mu \mathrm{m}$ inner diameter), which was glued to a holder that allowed easy manipulation of the tetrode. Next, the untwisted endings of the tetrode wires were soldered to the pins of an adapter fixed to the tetrode holder, allowing connection to the potentiostat's head-stage. Finally, the twisted ending of the tetrode was cut using micro-serrated stainless-steel scissors.

Tetrode surface treatments and platings were performed with a portable potentiostat (EmStat 3, PalmSens BV), using a freshly-prepared $\mathrm{Ag} / \mathrm{AgCl}$ wire $(125 \mu \mathrm{m}$ diameter, WPI inc.) as pseudoreference electrode. Prior to platings, electrode surfaces were cleaned by swirling the tetrode tip in isopropanol followed by an electrochemical treatment in PBS. For that purpose, we applied 70 cycles of a square wave with a first step at $+1.2 \mathrm{~V}$ for 20 seconds followed by a 4 seconds step at $-0.7 \mathrm{~V}$. All tetrode sites were then gold-plated in a $3.76 \mu \mathrm{M}$ aqueous solution of tetrachloroauric acid by applying 20 cycles of a square wave that alternated between $+0.6 \mathrm{~V}$ for $10 \mathrm{~s}$ and $-1.0 \mathrm{~V}$ for $10 \mathrm{~s}$. Sites' impedances were checked after gold-plating using a nanoZ impedance tester (Multichannel Systems, $\mathrm{GmbH})$. The pair of sites with the highest impedance was then platinized in a $10 \mathrm{mM}$ chloroplatinic acid solution in $0.1 \mathrm{M}$ sulfuric acid by DC amperometry at $-0.1 \mathrm{~V}$, until a current of $-30 \mathrm{nA}$ was reached.

\section{TACO sensor coatings}

Choline oxidase immobilization was performed as previously described (Santos et al., 2015). Briefly, a $0.5 \%(\mathrm{w} / \mathrm{v})$ chitosan stock solution was solubilized in saline $(0.9 \% \mathrm{NaCl})$ under stirring at $\mathrm{pH} 4-5$, adjusted by addition of $\mathrm{HCl}$. After solubilisation, the $\mathrm{pH}$ was set to 5-5.6 by stepwise addition of $\mathrm{NaOH}$. 
1 To form a chitosan/ChOx cross-linked matrix, $1.5 \mathrm{mg}$ of p-benzoquinone was added to $100 \mu \mathrm{L}$ of $20.2 \%$ chitosan. Four $\mu \mathrm{L}$ of this solution were then mixed with a $4 \mu \mathrm{L}$ aliquot of ChOx at $50 \mathrm{mg} / \mathrm{mL}$ in 3 saline. The tetrode tip was coated by multiple dips (10-15) in a small drop of ChOx immobilization 4 mixture, created using a microliter syringe (Hamilton Co.). The microelectrode and syringe were 5 micromanipulated under a stereomicroscope. The coating procedure was stopped when the 6 chitosan/protein matrix was clearly visible under the microscope.

7 Following enzyme immobilization, tetrode site's response to $\mathrm{Ch}$ was tested and meta8 phenylenediamine ( $m$-PD) was electropolymerized on the pair of sites with the highest sensitivity 9 (please see Biosensor calibrations sub-section). Electropolymerization was performed in a nitrogen 10 bubbled oxygen-free PBS solution of $5 \mathrm{mM} m$-PD by DC amperometry at $+0.6 \mathrm{~V}$ during $1500 \mathrm{~s}$. The biosensors were stored in air and calibrated on the day after $m$-PD electropolymerization.

\section{Biosensor calibrations}

All in vitro tests were done in a stirred calibration buffer kept at $37^{\circ} \mathrm{C}$ using a circulating water pump (Gaymar heating/cooling pump, Braintree Scientific, Inc., USA) connected to the calibration beaker. Routine calibrations after enzyme immobilization and $m$-PD electropolymerization steps were performed by amperometry at a DC potential of $+0.6 \mathrm{~V}$ vs. $\mathrm{Ag} / \mathrm{AgCl}$ pseudo-reference electrode. After stabilization of background current in PBS, sensors were calibrated by three consecutive additions of $10 \mu \mathrm{M}$ Ch followed by $4.9 \mu \mathrm{M} \mathrm{H}_{2} \mathrm{O}_{2}$. In the case of complete ( $m$-PD polymerized) biosensors, the response to $1 \mu \mathrm{M}$ DA and $100 \mu \mathrm{M}$ AA was also tested. Voltammograms of $\mathrm{H}_{2} \mathrm{O}_{2}$ were done by consecutive additions of $4.9 \mu \mathrm{M} \mathrm{H}_{2} \mathrm{O}_{2}$ at different applied DC voltages.

In vitro $\mathrm{O}_{2}$ tests were carried out in a sealed beaker. After addition of $5 \mu \mathrm{M} \mathrm{Ch}$, the calibration buffer was bubbled with nitrogen during approximately $30 \mathrm{~min}$. Then, known $\mathrm{O}_{2}$ concentrations $(5$ or 10 $\mu \mathrm{M})$ were added to the medium from an $\mathrm{O}_{2}$-saturated PBS solution previously bubbled with pure $\mathrm{O}_{2}$ during $20 \mathrm{~min}$. Biosensor response to $\mathrm{O}_{2}$ additions was measured at $+0.6 \mathrm{~V}$ vs. $\mathrm{Ag} / \mathrm{AgCl}$. In a set of calibrations, $\mathrm{O}_{2}$ was concurrently measured by polarizing a gold-plated channel at $-0.2 \mathrm{~V}$, while keeping the remaining at $+0.6 \mathrm{~V}$. To obtain $\mathrm{O}_{2}$ voltammograms, calibrations consisting in 3 additions of $5 \mu \mathrm{M} \mathrm{O}_{2}$ were performed at different applied DC potentials. In these experiments, $\mathrm{O}_{2}$ was purged from the solution after each voltage step.

\section{Experimental model and subject details}

Freely-moving recordings were performed on a 6 months old Long-Evans rat and head-fixed recordings were done in a total of six 3-7 month old C57BL/6J mice. All experimental procedures were established, and have been approved in accordance with the stipulations of the German animal welfare law (Tierschutzgesetz )(ROB-55.2-2532.Vet_02-16-170). 


\section{$1 \quad$ Surgeries}

2 For freely-moving recordings, we chronically implanted a tetrode biosensor and a 32-channel linear 3 silicon probe array (A1x32-7mm-100-1250-H32, NeuroNexus Technologies, Inc) in the rat brain. The general procedures for chronic implantations of electrode arrays have been described in detail (Vandecasteele et al., 2012). Prior to surgery, the tetrode biosensor and the silicon probe array were attached to home-made microdrives. Silicon probe's sites were then gold-plated until impedances at 1 $\mathrm{kHz}$ decreased below $200 \mathrm{k} \Omega$ (Ferguson et al., 2009). Anesthesia was induced with a mixture of Fentanyl $0.005 \mathrm{mg} / \mathrm{kg}$, Midazolam $2 \mathrm{mg} / \mathrm{kg}$ and Medetomidine $0.15 \mathrm{mg} / \mathrm{kg}$ (MMF), administered intramuscularly. The rat was continuously monitored for the depth of anesthesia (MouseStat, Kent Scientific Corporation, Inc.). After the MMF effect washed out, anesthesia was maintained with 0.5$2 \%$ isoflurane via a mask, and metamizol was then subcutaneously administered $(110 \mathrm{mg} / \mathrm{kg})$ for analgesia. The tetrode biosensor was implanted in the cortex above the right dorsal hippocampus (AP $-3.7 \mathrm{~mm}, \mathrm{ML}-2.5 \mathrm{~mm}, \mathrm{DV}-1.2 \mathrm{~mm}$, relative to bregma) and the silicon probe array was implanted at $0.8 \mathrm{~mm}$ posterior from it, spanning most cortical and hippocampal layers (AP -4.5, ML -2.4, DV 3.4). The microdrives were secured to the skull with a prosthetic resin (Paladur, Kulzer $\mathrm{GmbH})$. An $\mathrm{Ag} / \mathrm{AgCl}(125 \mu \mathrm{m}$ thick) silver wire coated with Nafion (Hashemi et al., 2011) was inserted in the cerebellum and served as the pseudo-reference electrode for electrochemical recordings. The ground for electrophysiology was a stainless-steel screw implanted at the surface of the cerebellum. To reduce line noise, this $\mathrm{Ag} / \mathrm{AgCl}$ wire was shorted with the electrophysiology ground at the input of the electrochemical head-stage.

Mice used in head-fixed recordings were implanted with a head-post. Anesthesia followed the same procedures as in rats. A mixture of $0.05 \mathrm{mg} / \mathrm{kg}$ Fentanyl, $5 \mathrm{mg} / \mathrm{kg}$ Midazolam and $0.5 \mathrm{mg} / \mathrm{kg}$ Medetomidine was administered intraperitoneally to induce anesthesia, which was later maintained with isoflurane and Metamizol (200 mg/kg). A craniotomy was made above the dorsal hippocampus and a Nafion-coated $\mathrm{Ag} / \mathrm{AgCl}$ wire was implanted in the cerebellum. Depending on the head-post configuration, it was cemented either to the back of the skull above the cerebellum or above the hemisphere contralateral to the craniotomy, using UV-curing dental cement (Tetric EvoFlow, Ivoclar Vivadent AG). Finally, the craniotomy and surrounding skull were covered with a silicone elastomer (KWIK-CAST, World Precision Instruments Inc.).

\section{Electrochemical and electrophysiological equipment and recordings}

Amperometric measurements were performed using either a 4-channel (MHS-BR4-VA) or a 8channel (MBR08-VA) potentiostat connected to 4- or 8-channel miniature head-stages, respectively (npi electronic $\mathrm{GmbH}$, Germany). In addition to providing a higher channel count, the MBR08-VA allowed independent control of the potential applied to each channel. This feature enabled simultaneous measurement of the biosensor signal, arising from $\mathrm{ChOx}$, and $\mathrm{O}_{2}$. The $\mathrm{DC}$ analog signal 
from the head-stage was amplified and digitized at $30 \mathrm{kHz}$ and stored for offline processing using the Open Ephys acquisition board and GUI (Siegle et al., 2017).

Freely-moving electrochemical recordings were done using the MHS-BR4-VA potentiostat and the corresponding 4-channel miniature head-stage. Electrophysiological signals were pre-amplified using a 32-channel head-stage with 20x gain (HST/32V-G20, Plexon Inc.) which was connected to a multichannel acquisition system (Neuralynx Inc). Data was acquired at $32 \mathrm{kHz}$ and stored for offline processing. Both head-stages were connected to the respective recording systems via light and flexible cables suspended on a pulley so as not to add weight to the animal's head. The tetrode biosensor was gradually lowered through the cortex until it reached the hippocampal CA1 pyramidal layer. Correct targeting was assessed based on brain atlas coordinates and by the identification of hippocampal ripples. Recordings were performed in a square open-field arena $(1.5 \mathrm{~m} \times 1.5 \mathrm{~m})$, where the animal could sleep or explore the environment at will. Chocolate sprinkles were occasionally spread on the maze to enforce exploratory behavior. The position of the rat head was derived from small reflective markers attached to the chronic implant. A motion capture system consisting of multiple infrared cameras (Optitrack, NaturalPoint Inc.) was used to 3D-track the markers with high spatio-temporal resolution (data acquired at $120 \mathrm{~Hz}$ ).

Head-fixed recordings in mice were performed using the MBR08-VA potentiostat and respective head-stage. After fixing the mouse, the layer of silicone elastomer protecting the craniotomy was removed. The dura matter above the target brain region was removed and the tetrode biosensor was slowly inserted through the cortex until the hippocampal CA1 pyramidal layer was reached. Accurate targeting was assessed according to brain atlas coordinates and/or by the online identification of hippocampal ripples in the recording. In 5 out of 10 recording sessions mice were head-fixed on a cylindrical treadmill. Movement was quantified based on the video optical flow arising from treadmill rotation using Bonsai (Lopes et al., 2015). In the remaining sessions, mice were head-fixed on a rotating disc which encoded its turns. The analog signal from the disc encoder was fed into the Open Ephys acquisition board and used to quantify mice locomotion.

\section{Data analysis}

Raw recordings were preprocessed by low-pass filtering and resampling at $1 \mathrm{kHz}$. All data analysis was done in Matlab using custom-made functions (MathWorks).

\section{In vitro sensor responses}

In vitro analysis of biosensor responses was performed on $10 \mathrm{~Hz}$ downsampled data, low-pass filtered at $1 \mathrm{~Hz}$. Sensitivities to $\mathrm{Ch}$ and $\mathrm{O}_{2}$ were determined by linear-regression of the responses to the first 3 analyte additions, whereas the sensitivities to $\mathrm{H}_{2} \mathrm{O}_{2}$ and interferents were estimated from a single addition. Minimal selectivity ratios were estimated by dividing the lower limit of the $95 \%$ confidence 
interval (CI) of Ch sensitivity by the upper limit of the CI of interferent responses. Following pseudosentinel subtraction, the biosensors' limit of detection (LOD) for $\mathrm{Ch}$ was calculated as the $\mathrm{Ch}$ concentration corresponding to 3 times the baseline standard deviation (SD). The $\mathrm{T}_{50}$ and $\mathrm{T}_{90}$ response times were defined as the time between the onset of current increase in response analyte and $50 \%$ or $90 \%$ of the maximum current, respectively.

\section{Artifact cancellation by common-mode rejection}

In vivo electrochemical signals from $\mathrm{Ch}$ - or $\mathrm{O}_{2}$-sensitive sites were cleaned by subtraction of the respective $1 \mathrm{kHz}$ data by the pseudo-sentinel (Au-Pt/m-PD) channel upon a frequency-domain correction. The latter procedure has been described in detail and optimizes common-mode rejection by correcting phase and amplitude mismatches between channels arising from slight variations in impedance (Santos et al., 2015). This correction was based on the estimation of a transfer coefficient (T) describing the transfer of LFP-currents from Sentinel to the Ch-sensitive (ChSens) channel in the complex domain, according to the following equation:

$$
C h(j w)=C h \operatorname{Sens}(j w)-T(j w) \operatorname{Sentinel}(j w)
$$

where $j w$ is a complex value at frequency $w$ and $C h$ is the clean putative $C h$ signal. Upon applying a fast Fourier transformation (FFT) on both signals, the amplitude of $T$ for each FFT frequency bin was estimated from the square root of ratio between the power of ChSens and sentinel channels. The phase of $\mathrm{T}$ was estimated from the phase of the ChSens/sentinel cross-spectrum (phase-shift) during timewindows with high phase-locking $(>0.98)$. These estimations were computed for each biosensor used in vivo from average spectra obtained from multiple slow-wave periods. In the low frequency range $(<0.3 \mathrm{~Hz})$, due Ch contribution to power in the ChSens channel, the estimation of the amplitude of $T$ was done by linear extrapolation considering the trend at contiguous higher frequencies. The cleaned signal of putative $C h$ was obtained by inverse FFT of $C h(j w)$. Cleaned $\mathrm{O}_{2}$ signals were obtained following the same logic.

Clean $\mathrm{Ch}$ and $\mathrm{O}_{2}$ signals were then low-pass filtered at $1 \mathrm{~Hz}$ and downsampled to $10 \mathrm{~Hz}$ for most of the analysis excluding time lags, which were computed on $100 \mathrm{~Hz}$ downsampled data.

\section{Brain state separation}

Local-field potential-related power spectrograms were computed using custom-made Matlab functions based on multi-taper analysis methods (Mitra and Pesaran, 1999). Separation of brain states in freely-moving recordings was based on LFP spectral features and behavior. Active wake states were defined as periods when the animal moved vigorously and continuously ( $>30 \mathrm{~s})$ and showed a prominent LFP spectral peak in theta range $(6-10 \mathrm{~Hz})$. Quiet wakefulness or immobility was defined as a period without prominent theta and with occasional movements $(<30 \mathrm{~s}$ between movement 
bouts). Long periods ( $>1 \mathrm{~min}$ ) without movement and without prominent theta, rather showing high delta power $(1-4 \mathrm{~Hz})$ were ascribed to NREM sleep. Rapid eye movement sleep was detected as periods showing a sustained theta band ( $>30 \mathrm{~s})$ and negligible movement.

\section{$4 \quad$ Sharp-wave/ripples and related biosensor signals}

5 To detect SWRs, the wide-band electrochemical or electrophysiological signal was band-pass filtered

6 (120-200 Hz), squared and smoothed with a $4.2 \mathrm{~ms}$ standard deviation and $42 \mathrm{~ms}$ wide Gaussian

7 kernel. The square root of this trace was then used as the power envelope to detect oscillatory bursts.

8 The events exceeding the $98^{\text {th }}$ percentile of the power envelope distribution, having at least 5 cycles 9 and lasting less than $200 \mathrm{~ms}$ were detected as ripples. For the analysis of correlations between 10 integrated ripple power and SWR-triggered sensor signals, a ripple power envelope was obtained upon Hilbert-transforming the band-pass filtered electrochemical signal (ripple band, 120-200 Hz). Different ripple integration times were obtained by smoothing the power envelope with moving average windows of different lengths. Correlations were then computed between smoothed ripple power envelopes at SWR times and the corresponding changes in COA or $\mathrm{O}_{2}$ (relative to their baseline value 1s prior to SWRs) at different lags from SWRs.

The amplitudes of SWR-related COA and $\mathrm{O}_{2}$ were obtained from the difference between the values at SWR lags corresponding to peaks and onsets, extracted from average SWR-triggered traces.

\section{Locomotion bouts}

To detect locomotion bouts in freely-moving recordings, speed was computed from the derivative of low-pass filtered position $(0.5 \mathrm{~Hz})$. Speed was then band-pass filtered $(0.02-0.2 \mathrm{~Hz})$ and locomotion bouts were detected as peaks in speed that exceeded a manually-set threshold. In head-fixed recordings on the disc, mouse locomotion was derived from its rotation in $1 \mathrm{~s}$ bins. When head-fixed on the treadmill, mouse locomotion was quantified based on the optic flow from a recorded video, choosing a region of interest that covered only a moving part of the treadmill. The signal was resampled to $1 \mathrm{~Hz}$ in order to match the sampling rate of locomotion on the rotating disc. Locomotion bouts were detected as peaks on the band-pass filtered speed $(0.02-0.2 \mathrm{~Hz})$ that exceeded a manuallydefined threshold.

The amplitude of locomotion-bout-associated $\mathrm{COA}$ and $\mathrm{O}_{2}$ signal transients was calculated based on the difference between the values at manually-determined times of transient onsets and peaks, associated with each event. Likewise, the times of locomotion bout onsets (used to calculate speed change) and the associated peaks in theta power were manually defined based on visual inspection of speed time courses and LFP spectrograms, respectively. 


\section{Oxygen-related $\mathrm{ChOx}$ transient signals analysis}

2 The amplitude of broad-band spontaneous and exogenously-induced $\mathrm{O}_{2}$ transients and COA transients

3 associated with them was calculated, for each event, as the difference between the peak value and that

4 at semi-automatically defined time of the transient's onset.

5 To capture and separately analyze spontaneous $\mathrm{COA}$ and $\mathrm{O}_{2}$ transients of highly variable timescale (1-

614 seconds) and non-harmonic shape we performed peak detection on the two signals band-pass

7 filtered in a frequency range $[f / 2 f]$ with corner frequency $f$, defining each filter, varying from 0.05 to

$8 \quad 0.5 \mathrm{~Hz}$. Peaks of the transients were then detected in both band-passed COA and $\mathrm{O}_{2}$ signals, selecting

9 the events that exceeded half of the maximal peak amplitude. In each frequency band, COA transients

10 used for the analysis were restricted to be within $0.75 / f$ of any $\mathrm{O}_{2}$ peak. The amplitudes of $\mathrm{O}_{2}$ and

11 COA transients were defined as peak magnitudes derived from the band-pass filtered signals. For each

12 filter band, the linear relationship between $\mathrm{COA}$ and $\mathrm{O}_{2}$ peak amplitudes was estimated as a slope of

13 the linear model fit to all detected event pairs for this filter. To interpret the nonlinear shape of the $\mathrm{O}_{2}$

14 transients captured by each filter, we extracted rise time (from trough to peak) from the median peak

15 aligned $\mathrm{O}_{2}$ transients and used these values in Figures 4E-H.

16 The transient onsets and peaks of exogenously-induced changes in $\mathrm{O}_{2}$ and $\mathrm{CAO}$ were manually 17 detected.

We simulated biosensor responses in vitro by numerically solving a system of partial differential equations that describe the diffusion of the substrates $\mathrm{Ch}$ and $\mathrm{O}_{2}$ in the enzyme coating and their interaction with the enzyme, leading to product formation.

The buffer solution where the biosensor was placed for calibration is a free-flow environment, in which the concentrations of $\mathrm{Ch}$ and $\mathrm{O}_{2}$ are constant over time. Therefore, considering $R$ is the coating thickness, at the boundary between the biosensor coating and the calibration buffer $\mathrm{Ch}$ is kept constant at $5 \mu \mathrm{M}$ during the calibration. 
1 Enzyme substrates $\left(\mathrm{Ch}\right.$ and $\left.\mathrm{O}_{2}\right)$ diffuse from the bulk solution into the enzyme layer, eventually

2 reaching the electrode site, whereas $\mathrm{H}_{2} \mathrm{O}_{2}$ is locally generated and diffuses within the coating. As the

3 size of our recording sites is very small, this process is better described by a spherical diffusion

4 equation:

$$
D_{i f_{S}}=\frac{\partial[S]}{\partial t}=D_{S} \frac{1}{r^{2}} \frac{\partial}{\partial r}\left(r^{2} \frac{\partial[S]}{\partial r}\right)
$$

5 where $S$ represents substrates or $\mathrm{H}_{2} \mathrm{O}_{2}$ concentration, $D_{S}$ is the respective diffusion coefficient and $r$ is 6 the distance to the electrode surface.

7 In order to simulate realistic two-substrate biosensor responses, we modeled the formation of enzyme 8 intermediate complexes resulting from $\mathrm{Ch}$ binding to the enzyme and $\mathrm{O}_{2}$ oxidation reactions, which 9 have been described in detail (Fan and Gadda, 2005) (Scheme 1). Briefly, enzyme-bound Ch (ECh), which is in equilibrium with the free reactant species $(E$ and $C h)$, undergoes a chemical step leading to the reduction of the FAD enzyme prosthetic group. In this nearly irreversible step, $\mathrm{Ch}$ is converted to betaine aldehyde, which remains mostly enzyme-bound $\left(E_{\mathrm{red}} \mathrm{BA}\right)$. The first step in which $\mathrm{H}_{2} \mathrm{O}_{2}$ is produced results from the oxidation of $\mathrm{FAD}_{\text {red }}$ by $\mathrm{O}_{2}\left(E_{o x} B A\right)$ followed by a second chemical step in which $\mathrm{FAD}_{\mathrm{ox}}$ is reduced by betaine aldehyde. The resulting enzyme-bound glycine betaine $\left(E_{\text {red }} G B\right)$ is then oxidized by $\mathrm{O}_{2}$, producing $\mathrm{H}_{2} \mathrm{O}_{2}$. The reaction cycle is completed with release of glycine betaine bound to FAD-oxidized enzyme $\left(E_{o x} G B\right)$. partial differential equations:

$$
\begin{aligned}
\frac{\partial[E]}{\partial t} & =-k f[E][C h]+k r[E C h]+k_{5}\left[E_{o x} G B\right] \\
\frac{\partial[C h]}{\partial t} & =D i f_{C h}-k f[E][C h]+k r[E C h] \\
\frac{\partial[E C h]}{\partial t} & =k f[E][C h]-k r[E C h]-k_{1}[E C h] \\
\frac{\partial\left[O_{2}\right]}{\partial t} & =D i f_{O_{2}}-k_{2}\left[E_{r e d} B A\right]\left[O_{2}\right]-k_{4}\left[E_{r e d} G B\right]\left[O_{2}\right] \\
\frac{\partial\left[E_{r e d} B A\right]}{\partial t} & =k_{1}[E C h]-k_{2}\left[E_{r e d} B A\right]\left[O_{2}\right] \\
\frac{\partial\left[E_{o x} B A\right]}{\partial t} & =k_{2}\left[E_{r e d} B A\right]\left[O_{2}\right]-k_{3}\left[E_{o x} B A\right] \\
\frac{\partial\left[E_{r e d} G B\right]}{\partial t} & =k_{3}\left[E_{o x} B A\right]-k_{4}\left[E_{r e d} G B\right]\left[O_{2}\right] \\
\frac{\partial\left[E_{o x} G B\right]}{\partial t} & =-k_{5}\left[E_{o x} G B\right]+k_{4}\left[E_{r e d} G B\right]\left[O_{2}\right] \\
\frac{\partial\left[H_{2} O_{2}\right]}{\partial t} & =D i f_{H_{2} O_{2}}+k_{2}\left[E_{r e d} B A\right]\left[O_{2}\right]+k_{4}\left[E_{r e d} G B\right]\left[O_{2}\right]
\end{aligned}
$$


1 Note that we ignored the kinetics of glycine betaine formation, as it is not relevant regarding the

2 sensor signal transduction and it would not affect the concentrations of any reaction species.

3 In the beginning of the simulated calibration, there is no $\mathrm{Ch}$ in the coating, so all enzyme molecules

4 are free, at a concentration that equals the total enzyme concentration $\left([E]_{0}\right)$.

5

$6 \quad[E]\left(r, t_{0}\right)=[E]_{0} \quad r=r_{1}, \ldots, R$.

7

8 In turn, in the same conditions, there are no enzyme-bound species and no product formed.

9

$[E C h]\left(r, t_{0}\right)=\left[E_{\text {red }} B A\right]\left(r, t_{0}\right)=\left[E_{o x} B A\right]\left(r, t_{0}\right)=\left[E_{\text {red }} G B\right]\left(r, t_{0}\right)=\left[E_{o x} G B\right]\left(r, t_{0}\right)=\left[H_{2} O_{2}\right]\left(r, t_{0}\right)=0$,

$r=r_{1}, \ldots, R$.

At the electrode surface there is zero flux of substrates and $\mathrm{H}_{2} \mathrm{O}_{2}$ is rapidly oxidized, whereas at the boundary between the coating and bulk solution it is rapidly washed away.

$\left.\frac{\partial C h}{\partial t}\right|_{r l}=0,\left.\quad \frac{\partial O_{2}}{\partial t}\right|_{r l}=0, \quad\left[H_{2} O_{2}\right]\left(r_{1}\right)=0 \quad$ and $\left[H_{2} O_{2}\right](R)=0$

The sensor response current is then given by the charge of two-electrons per each oxidized $\mathrm{H}_{2} \mathrm{O}_{2}$ molecule times the flux of $\mathrm{H}_{2} \mathrm{O}_{2}$ at the electrode surface.

$I=2 F\left(\pi r_{e}^{2}\right) J_{H 2 O 2}, \quad J_{H 2 O 2}=\left.D_{\mathrm{H}_{2} \mathrm{O}_{2}} \frac{\partial \mathrm{H}_{2} \mathrm{O}_{2}}{\partial r}\right|_{r l}$,

where $F$ is the Faraday's constant and $\pi r_{e}^{2}$ is the electrode surface area.

Considering the initial conditions described above the system of partial differential equations was numerically solved by discretization in space and time (time and space steps $d t=0.1 \mathrm{~ms}$ and $d r=1$ $\mu \mathrm{m}$, respectively) using the finite difference approximation method (Baronas et al., 2009).

The values ascribed to the variables used in the model are summarized in Table 2 . The rate constants corresponding to the reaction mechanism in Scheme 1 were extracted from the corresponding literature (Fan and Gadda, 2005). An enzyme concentration in the coating of $263 \mathrm{uM}$ was estimated from its concentration in the mixture used for coatings, ignoring drying effects upon coating. Variations in enzyme concentration were simulated around that value. We estimated the diffusion coefficients of enzyme substrates and $\mathrm{H}_{2} \mathrm{O}_{2}$ in the coating taking into account the free diffusion coefficients in solution multiplied by a hindrance factor $\alpha$. The latter was set at 0.8 , considering the expected effect of macromolecular crowding on diffusion, for protein concentrations in the range of those used in our simulations (Lamers-Lemmers et al., 2000; Santos et al., 2011) 


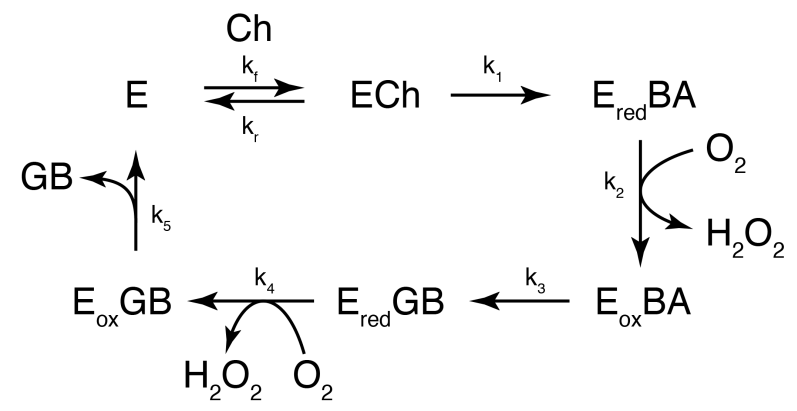

1 Scheme 1. Minimal kinetic mechanism of Choline Oxidase. (E) Free enzyme, (ECh) enzyme-bound Ch,

$2\left(\mathrm{E}_{\mathrm{red}}\right)$ enzyme with reduced FAD co-factor, $\left(\mathrm{E}_{\mathrm{ox}}\right)$ enzyme with oxidized FAD co-factor, $(\mathrm{BA})$ betaine aldehyde,

3 (GB) glycine betaine. 
Table 2. Values of constants used in the biosensor model

\begin{tabular}{|l|l|l|}
\hline Constant & Value & Reference \\
\hline $\mathrm{k}_{\mathrm{f}}{ }^{*}$ & $2 \times 10^{6} M^{-1} s^{-1}$ & (Fan and Gadda, 2005) \\
\hline $\mathrm{k}_{\mathrm{r}}{ }^{*}$ & $580 s^{-1}$ & (Fan and Gadda, 2005) \\
\hline $\mathrm{k}_{1}$ & $93 s^{-1}$ & (Fan and Gadda, 2005) \\
\hline $\mathrm{k}_{2}$ & $8.64 \times 10^{4} M^{-1} s^{-1}$ & (Fan and Gadda, 2005) \\
\hline $\mathrm{k}_{3}$ & $135 \mathrm{~s}^{-1}$ & (Fan and Gadda, 2005) \\
\hline $\mathrm{k}_{4}$ & $5.34 \times 10^{4} M^{-1} s^{-1}$ & (Fan and Gadda, 2005) \\
\hline $\mathrm{k}_{5}$ & $200 \mathrm{~s}^{-1}$ & (Fan and Gadda, 2005) \\
\hline $\mathrm{D}_{\mathrm{Ch}}{ }^{* *}$ & $1197 \mu m^{2} s^{-1}$ & (Valencia and González, 2012) \\
\hline $\mathrm{D}_{\mathrm{O} 2}{ }^{* * *}$ & $2500 \mu m^{2} s^{-1}$ & (Santos et al., 2011) \\
\hline $\mathrm{D}_{\mathrm{H} 2 \mathrm{O} 2}$ & $1830 \mu m^{2} s^{-1}$ & (van Stroe-Biezen et al., 1993) \\
\hline$\alpha$ & 0.8 & \\
\hline
\end{tabular}

Estimated based on $\mathrm{K}_{\mathrm{d}}, \mathrm{K}_{\mathrm{cat}}$ and $\mathrm{K}_{\mathrm{m}}$ values of ChOx for choline

${ }^{* *}$ Estimated using the Stokes-Einstein Gierer-Wirtz Estimation method

*** Extrapolated from room temperature to $37^{\circ} \mathrm{C}$ using a factor of $2.6 \%$ per degree (Han and Bartels, 1996). 


\section{$1 \quad$ Statistical analysis}

2 All statistical tests were performed using Matlab. Prior to statistical comparisons, the normality of the

3 data was tested by a Anderson-Darling test. In the case of non-normal distributions, comparisons

4 between two groups were performed using a non-parametric two-sided sign test (signtest, Matlab). To

5 test the effect of two factors on non-normal data (effect of ripple count and power on $\mathrm{COA}$ or $\mathrm{O}_{2}$

6 transients), an aligned-rank-transformation (Wobbrock et al., 2011) was applied followed by two-way

7 ANOVA for unbalanced data (nanova, Matlab). Whenever normality could not be discarded, two-

8 sided two-sample $t$-tests (paired or unpaired) were used to compare two groups. Two-sided one-

9 sample $t$-tests were used to test deviations from the null hypothesis (zero). Multiple comparisons were

10 done by one-way ANOVA for unbalanced data. The effect of two or more factors was accounted for

11 by two- or three-way ANOVA for unbalanced data.

12 Data were presented as average $\pm 95 \%$ confidence interval (CI) to allow easy assessment of the 13 significance of estimates. Average corresponds to the mean in normal data or to the median otherwise.

14 The CI of medians was computed based on fractional order statistics (Hutson, 1999). Confidence 15 intervals for correlation coefficients and COA vs. $\mathrm{O}_{2}$ slopes were computed from the percentiles 2.5 and 97.5 of bootstrapped data.

\section{Acknowledgments}

19 This work was supported by Bundesministerium für Bildung und Forschung [grant number 01GQ0440] and the Munich Cluster for Systems Neurology [grant number SyNergy EXC 1010]. We would like to thank Francisco Almeida and Kenneth Klau for technical assistence.

\section{Competing interests}

The authors declare no competing interests. 


\section{References:}

Baker, K.L., Bolger, F.B., and Lowry, J.P. (2015). A microelectrochemical biosensor for real-time in vivo monitoring of brain extracellular choline. Anal. 140, 3738-3745.

Baker, K.L., Bolger, F.B., and Lowry, J.P. (2017). Development of a microelectrochemical biosensor for the real-time detection of choline. Sensors Actuators B: Chem. 243.

Baronas, R., Ivanauskas, F., and Kulys, J. (2009). Mathematical modeling of biosensors: an introduction for chemists and mathematicians.

Brehm, R., Lindmar, R., and Löffelholz, K. (1987). Muscarinic mobilization of choline in rat brain in vivo as shown by the cerebral arterio-venous difference of choline. J. Neurochem. 48, 1480-1485.

Burke, L.D. (1996). Anomalous Oxidation Reactions at Noble Metal Surfaces at Low Potentials: With Particular Reference to Palladium. J. Electrochem. Soc. 143.

Burke, L.D., and Nugent, P.F. (1997). The electrochemistry of gold: I the redox behaviour of the metal in aqueous media. Gold Bull. 30 .

Burmeister, J.J., Palmer, M., and Gerhardt, G.A. (2003). Ceramic-based multisite microelectrode array for rapid choline measures in brain tissue. Anal. Chim. Acta 481.

Buzsáki, G. (2002). Theta oscillations in the hippocampus. Neuron 33, 325-340.

Buzsáki, G. (2015). Hippocampal sharp wave-ripple: A cognitive biomarker for episodic memory and planning. Hippocampus 25, 1073-1188.

Chatard, C., Meiller, A., and Marinesco, S. (2018). Microelectrode Biosensors for in vivo Analysis of Brain Interstitial Fluid. Electroanalysis 30.

Csernai, M., Borbély, S., Kocsis, K., Burka, D., Fekete, Z., Balogh, V., Káli, S., Emri, Z., and Barthó, P. (2019). Dynamics of sleep oscillations is coupled to brain temperature on multiple scales. J.

Physiol.

Dixon, B.M., Lowry, J.P., and O'Neill, R.D. (2002). Characterization in vitro and in vivo of the oxygen dependence of an enzyme/polymer biosensor for monitoring brain glucose. J. Neurosci. Methods 119, 135-142.

Domínguez-Domínguez, S., Arias-Pardilla, J., Berenguer-Murcia, Á., Morallón, E., and CazorlaAmorós, D. (2008). Electrochemical deposition of platinum nanoparticles on different carbon supports and conducting polymers. J. Appl. Electrochem. 38. 
Eggermann, E., Kremer, Y., Crochet, S., and Petersen, C.C.H. (2014). Cholinergic signals in mouse barrel cortex during active whisker sensing. Cell Reports 9, 1654-1660.

Fan, F., and Gadda, G. (2005). On the catalytic mechanism of choline oxidase. J. Am. Chem. Soc. 127, 2067-2074.

Ferguson, J.E., Boldt, C., and Redish, A.D. (2009). Creating low-impedance tetrodes by electroplating with additives. Sensors Actuators. Phys. 156, 388-393.

Garguilo, M.G., and Michael, A.C. (1996). Amperometric microsensors for monitoring choline in the extracellular fluid of brain. J. Neurosci. Methods 70, 73-82.

Gray, C.M., Maldonado, P.E., Wilson, M., and McNaughton, B. (1995). Tetrodes markedly improve the reliability and yield of multiple single-unit isolation from multi-unit recordings in cat striate cortex. J. Neurosci. Methods 63, 43-54.

Gu, Z., Alexander, G.M., Dudek, S.M., and Yakel, J.L. (2017). Hippocampus and Entorhinal Cortex Recruit Cholinergic and NMDA Receptors Separately to Generate Hippocampal Theta Oscillations. Cell Reports 21, 3585-3595.

Han, P., and Bartels, D.M. (1996). Temperature Dependence of Oxygen Diffusion in H2O and D2O. The Journal of Physical Chemistry 100.

Hangya, B., Ranade, S.P., Lorenc, M., and Kepecs, A. (2015). Central Cholinergic Neurons Are Rapidly Recruited by Reinforcement Feedback. Cell 162, 1155-1168.

Hascup, K.N., Hascup, E.R., Littrell, O.M., Hinzman, J.M., Werner, C.E., Davis, V.A., Burmeister, J.J., Pomerleau, F., Quintero, J.E., Huettl, P., et al. (2013). Microelectrode Array Fabrication and Optimization for Selective Neurochemical Detection. In Microelectrode Biosensors, (Humana Press), pp. $27-54$.

Hashemi, P., Walsh, P.L., Guillot, T.S., Gras-Najjar, J., Takmakov, P., Crews, F.T., and Wightman, R.M. (2011). Chronically Implanted, Nafion-Coated Ag/AgCl Reference Electrodes for Neurochemical Applications. ACS Chem. Neurosci. 2, 658-666.

Hasselmo, M.E., and McGaughy, J. High acetylcholine levels set circuit dynamics for attention and encoding and low acetylcholine levels set dynamics for consolidation. Prog Brain Res 145, 207-231.

Hasselmo, M.E., and McGaughy, J. (2004). High acetylcholine levels set circuit dynamics for attention and encoding and low acetylcholine levels set dynamics for consolidation. Prog. Brain Res. $145,207-231$. 
Hekmat, A., Saboury, A.A., Moosavi-Movahedi, A.A., Ghourchian, H., and Ahmad, F. (2008). Effects of $\mathrm{pH}$ on the activity and structure of choline oxidase from Alcaligenes species. Acta Biochim. Pol. 55, 549-557.

Howe, W.M., Gritton, H.J., Lusk, N.A., Roberts, E.A., Hetrick, V.L., Berke, J.D., and Sarter, M. (2017). Acetylcholine Release in Prefrontal Cortex Promotes Gamma Oscillations and Theta-Gamma Coupling during Cue Detection. J. Neurosci. Off. J. Soc. Neurosci. 37, 3215-3230.

Hutson, A.D. (1999). Calculating nonparametric confidence intervals for quantiles using fractional order statistics. J. Appl. Stat. 26, 343-353.

Lamers-Lemmers, J.P., Hoofd, L.J., and Oeseburg, B. (2000). Non-steady-state O(2) diffusion in metmyoglobin solutions studied in a diffusion chamber. Biochem. Biophys. Res. Commun. 276, $773-$ 778.

Leithner, C., and Royl, G. (2014). The oxygen paradox of neurovascular coupling. J. Cereb. Blood Flow Metab. Off. J. Int. Soc. Cereb. Blood Flow Metab. 34, 19-29.

Li, S., Topchiy, I., and Kocsis, B. (2007). The effect of atropine administered in the medial septum or hippocampus on high- and low-frequency theta rhythms in the hippocampus of urethane anesthetized rats. Synap. 61, 412-419.

Lopes, G., Bonacchi, N., Frazão, J., Neto, J.P., Atallah, B.V., Soares, S., Moreira, L., Matias, S., Itskov, P.M., Correia, P.A., et al. (2015). Bonsai: an event-based framework for processing and controlling data streams. Front. Neuroinformatics 9, 7.

Lovett-Barron, M., Kaifosh, P., Kheirbek, M.A., Danielson, N., Zaremba, J.D., Reardon, T.R., Turi, G.F., Hen, R., Zemelman, B.V., and Losonczy, A. (2014). Dendritic inhibition in the hippocampus supports fear learning. Sci. 343, 857-863.

Lyons, D.G., Parpaleix, A., Roche, M., and Charpak, S. (2016). Mapping oxygen concentration in the awake mouse brain. ELife 5 .

Marrosu, F., Portas, C., Mascia, M.S., Casu, M.A., Fà, M., Giagheddu, M., Imperato, A., and Gessa, G.L. (1995). Microdialysis measurement of cortical and hippocampal acetylcholine release during sleep-wake cycle in freely moving cats. Brain Res. 671, 329-332.

McMahon, C.P., Rocchitta, G., Kirwan, S.M., Killoran, S.J., Serra, P.A., Lowry, J.P., and O’Neill, R.D. (2007). Oxygen tolerance of an implantable polymer/enzyme composite glutamate biosensor displaying polycation-enhanced substrate sensitivity. Biosens. \& Bioelectron. 22, 1466-1473. 
Mikulovic, S., Restrepo, C.E., Siwani, S., Bauer, P., Pupe, S., Tort, A.B.L., Kullander, K., and Leão, R.N. (2018). Ventral hippocampal OLM cells control type 2 theta oscillations and response to predator odor. Nat. Commun. 9, 3638.

Mitra, P.P., and Pesaran, B. (1999). Analysis of dynamic brain imaging data. Biophys. J. 76, 691-708.

Murr, R., Berger, S., Schürer, L., Peter, K., and Baethmann, A. (1994). A novel, remote-controlled suspension device for brain tissue PO2 measurements with multiwire surface electrodes. Pflugers Arch. Eur. J. Physiol. 426, 348-350.

Nair, P.K., Buerk, D.G., and Halsey, J.H. (1987). Comparisons of oxygen metabolism and tissue PO2 in cortex and hippocampus of gerbil brain. Stroke 18, 616-622.

Njagi, J., Ispas, C., and Andreescu, S. (2008). Mixed ceria-based metal oxides biosensor for operation in oxygen restrictive environments. Anal. Chem. 80, 7266-7274.

Norimoto, H., Mizunuma, M., Ishikawa, D., Matsuki, N., and Ikegaya, Y. (2012). Muscarinic receptor activation disrupts hippocampal sharp wave-ripples. Brain Res. 1461, 1-9.

O’Neill, R.D., Chang, S.-C., Lowry, J.P., and McNeil, C.J. (2004). Comparisons of platinum, gold, palladium and glassy carbon as electrode materials in the design of biosensors for glutamate. Biosens. \& Bioelectron. 19, 1521-1528.

Parikh, V., Pomerleau, F., Huettl, P., Gerhardt, G. a, Sarter, M., and Bruno, J.P. (2004). Rapid assessment of in vivo cholinergic transmission by amperometric detection of changes in extracellular choline levels. Eur. J. Neurosci. 20, 1545-1554.

Parikh, V., Kozak, R., Martinez, V., and Sarter, M. (2007). Prefrontal acetylcholine release controls cue detection on multiple timescales. Neuron 56, 141-154.

Park, J., Kim, C.-S., and Choi, M. (2006). Oxidase-Coupled Amperometric Glucose and Lactate Sensors With Integrated Electrochemical Actuation System. IEEE Trans. Instrum. Meas. 55.

Ramirez-Villegas, J.F., Logothetis, N.K., and Besserve, M. (2015). Diversity of sharp-wave-ripple LFP signatures reveals differentiated brain-wide dynamical events. Proc. Natl. Acad. Sci. United States Am. 112, E6379-E6387.

Reimer, J., McGinley, M.J., Liu, Y., Rodenkirch, C., Wang, Q., McCormick, D.A., and Tolias, A.S. (2016). Pupil fluctuations track rapid changes in adrenergic and cholinergic activity in cortex. Nat. Commun. 7, 13289.

Santos, R.M., Lourenço, C.F., Piedade, A.P., Andrews, R., Pomerleau, F., Huettl, P., Gerhardt, G.A., 
Laranjinha, J., and Barbosa, R.M. (2008). A comparative study of carbon fiber-based microelectrodes for the measurement of nitric oxide in brain tissue. Biosens. \& Bioelectron. 24, 704-709.

Santos, R.M., Lourenço, C.F., Gerhardt, G.A., Cadenas, E., Laranjinha, J., and Barbosa, R.M. (2011). Evidence for a pathway that facilitates nitric oxide diffusion in the brain. Neurochem. Int. 59, 90-96.

Santos, R.M., Laranjinha, J., Barbosa, R.M., and Sirota, A. (2015). Simultaneous measurement of cholinergic tone and neuronal network dynamics in vivo in the rat brain using a novel choline oxidase based electrochemical biosensor. Biosens. \& Bioelectron. 69, 83-94.

Siegle, J.H., López, A.C., Patel, Y.A., Abramov, K., Ohayon, S., and Voigts, J. (2017). Open Ephys: an open-source, plugin-based platform for multichannel electrophysiology. J. Neural Eng. 14, 045003.

Steriade, M. (2004). Acetylcholine systems and rhythmic activities during the waking-sleep cycle. Prog. Brain Res. 145, 179-196.

van Stroe-Biezen, S.A.., Everaerts, F.., Janssen, L.J.., and Tacken, R.. (1993). Diffusion coefficients of oxygen, hydrogen peroxide and glucose in a hydrogel. Anal. Chim. Acta 273.

Takata, N., Nagai, T., Ozawa, K., Oe, Y., Mikoshiba, K., and Hirase, H. (2013). Cerebral blood flow modulation by Basal forebrain or whisker stimulation can occur independently of large cytosolic Ca2+ signaling in astrocytes. PloS One 8 , e66525.

Teles-Grilo Ruivo, L.M., and Mellor, J.R. (2013). Cholinergic modulation of hippocampal network function. Front. Synaptic Neurosci. 5, 2.

Teles-Grilo Ruivo, L.M., Baker, K.L., Conway, M.W., Kinsley, P.J., Gilmour, G., Phillips, K.G., Isaac, J.T.R., Lowry, J.P., and Mellor, J.R. (2017). Coordinated Acetylcholine Release in Prefrontal Cortex and Hippocampus Is Associated with Arousal and Reward on Distinct Timescales. Cell Reports 18, 905-917.

Valencia, D.P., and González, F.J. (2012). Estimation of diffusion coefficients by using a linear correlation between the diffusion coefficient and molecular weight. Journal of Electroanalytical Chemistry 681.

Vandecasteele, M., M, S., Royer, S., Belluscio, M., Berényi, A., Diba, K., Fujisawa, S., Grosmark, A., Mao, D., Mizuseki, K., et al. (2012). Large-scale recording of neurons by movable silicon probes in behaving rodents. J. Vis. Exp. JoVE e3568.

Vandecasteele, M., Varga, V., Berényi, A., Papp, E., Barthó, P., Venance, L., Freund, T.F., and Buzsáki, G. (2014). Optogenetic activation of septal cholinergic neurons suppresses sharp wave 
ripples and enhances theta oscillations in the hippocampus. Proc. Natl. Acad. Sci. United States Am. $111,13535-13540$.

Venton, B.J., Michael, D.J., and Wightman, R.M. (2003). Correlation of local changes in extracellular oxygen and $\mathrm{pH}$ that accompany dopaminergic terminal activity in the rat caudate-putamen. $\mathrm{J}$. Neurochem. 84, 373-381.

Viggiano, A., Marinesco, S., Pain, F., Meiller, A., and Gurden, H. (2012). Reconstruction of field excitatory post-synaptic potentials in the dentate gyrus from amperometric biosensor signals. J. Neurosci. Methods 206, 1-6.

Wobbrock, J.O., Findlater, L., Gergle, D., and Higgins, J.J. (2011). The aligned rank transform for nonparametric factorial analyses using only anova procedures. In Proceedings of the 2011 Annual Conference on Human Factors in Computing Systems - CHI '11, (ACM Press), p. 143.

Zhang, H., Lin, S.-C., and Nicolelis, M.A.L. (2009). Acquiring local field potential information from amperometric neurochemical recordings. J. Neurosci. Methods 179, 191-200.

Zhang, H., Lin, S.-C., and Nicolelis, M.A.L. (2010). Spatiotemporal coupling between hippocampal acetylcholine release and theta oscillations in vivo. J. Neurosci. Off. J. Soc. Neurosci. 30, $13431-$ 13440.

Zhang, Q., Roche, M., Gheres, K.W., Chaigneau, E., Kedarasetti, T., Haselden, D., Charpak, S., Drew, P. J. (2019). Cerebral oxygenation during locomotion is modulated by respiration. Nat. Commun. 10, 5515. 


\section{Supplementary Materials}

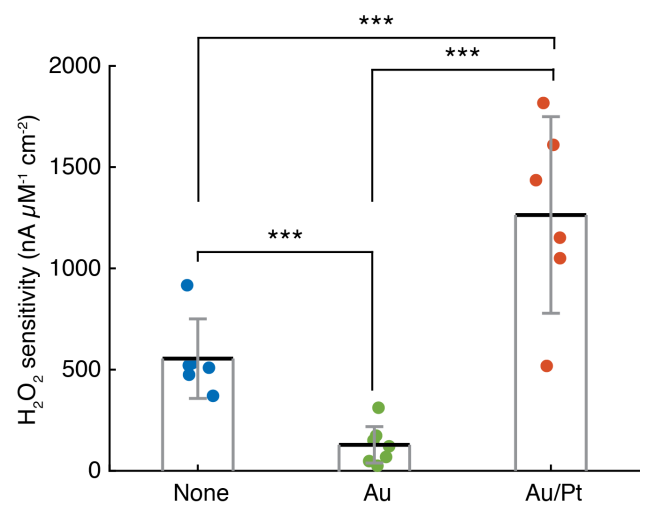

Figure S1. Effect of platings on platinum electrode sensitivity to $\mathbf{H}_{2} \mathbf{O}_{2}$. Normalized $\mathrm{H}_{2} \mathrm{O}_{2}$ sensitivity of $\mathrm{Pt} / \mathrm{Ir}$ disc electrodes ( $\mathrm{n}=6$, data from our previous sensor design (Santos et al., 2015)), gold-plated Pt/Ir tetrode sites $(\mathrm{n}=7)$ and gold/platinum plated tetrode sites $(\mathrm{n}=6)$. All electrode surfaces were coated with chitosan/ChOx matrices. All group pairwise comparisons were statistically significant $(p<0.001$, one-way ANOVA for 

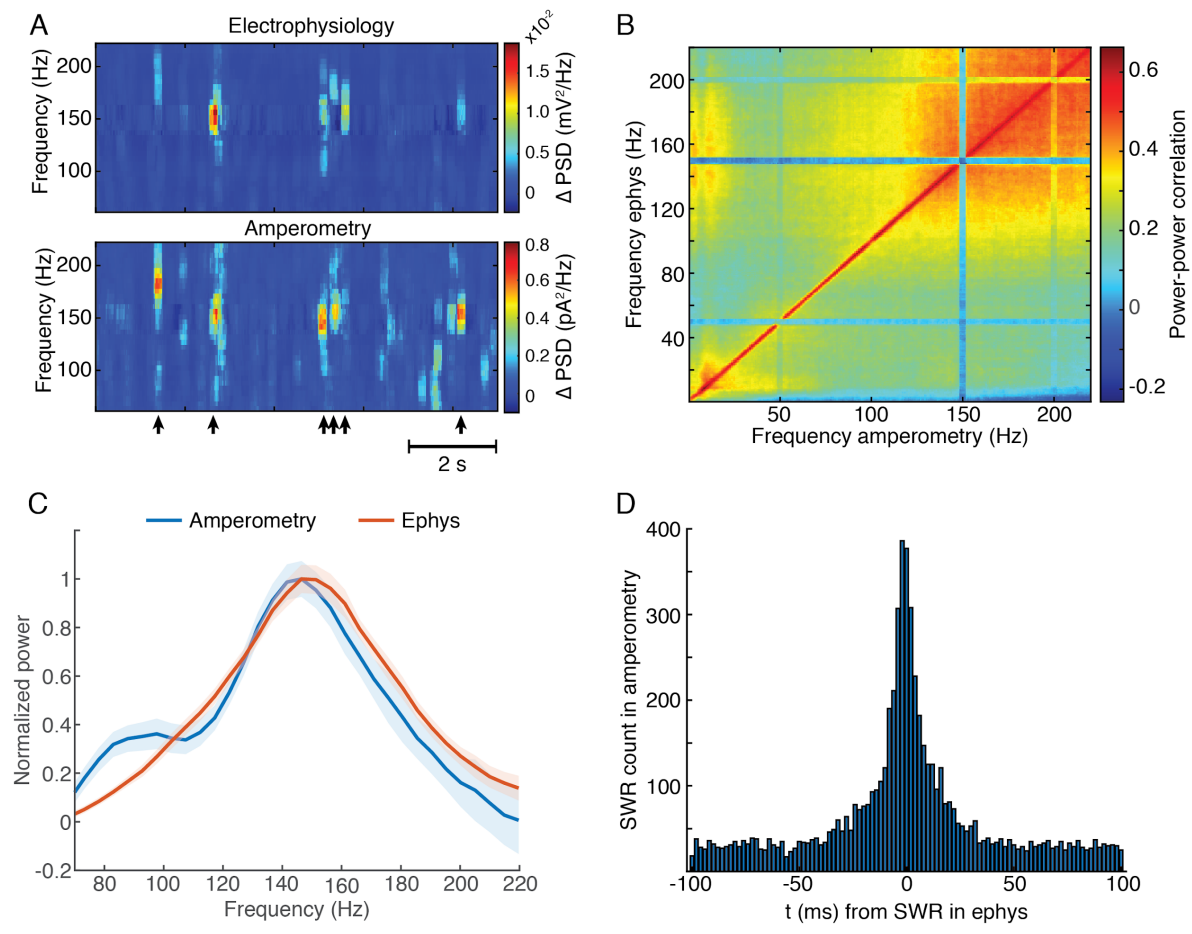

Figure S2. Amperometric currents reliably track LFP spectral content over a wide frequency range. (A) Representative power spectrogram from high-frequency range of electrophysiology and amperometry derived LFP signals in the CA1 pyramidal layer during NREM sleep. Arrows indicate timings of SWRs detected from LFP. (B) Comodugram showing the correlation between LFP power, recorded during NREM sleep, from a silicon probe's site in CA1 pyramidal layer and the power of the amperometric signal from a biosensor site, targeted to the same hippocampal layer. (C) Normalized power spectra triggered to SWRs using both modalities. (D) Cross-correlogram of SWR timings detected using amperometry and electrophysiology $(\mathrm{n}=8074$

8 for electrophysiology and n=8085 for amperometry). 

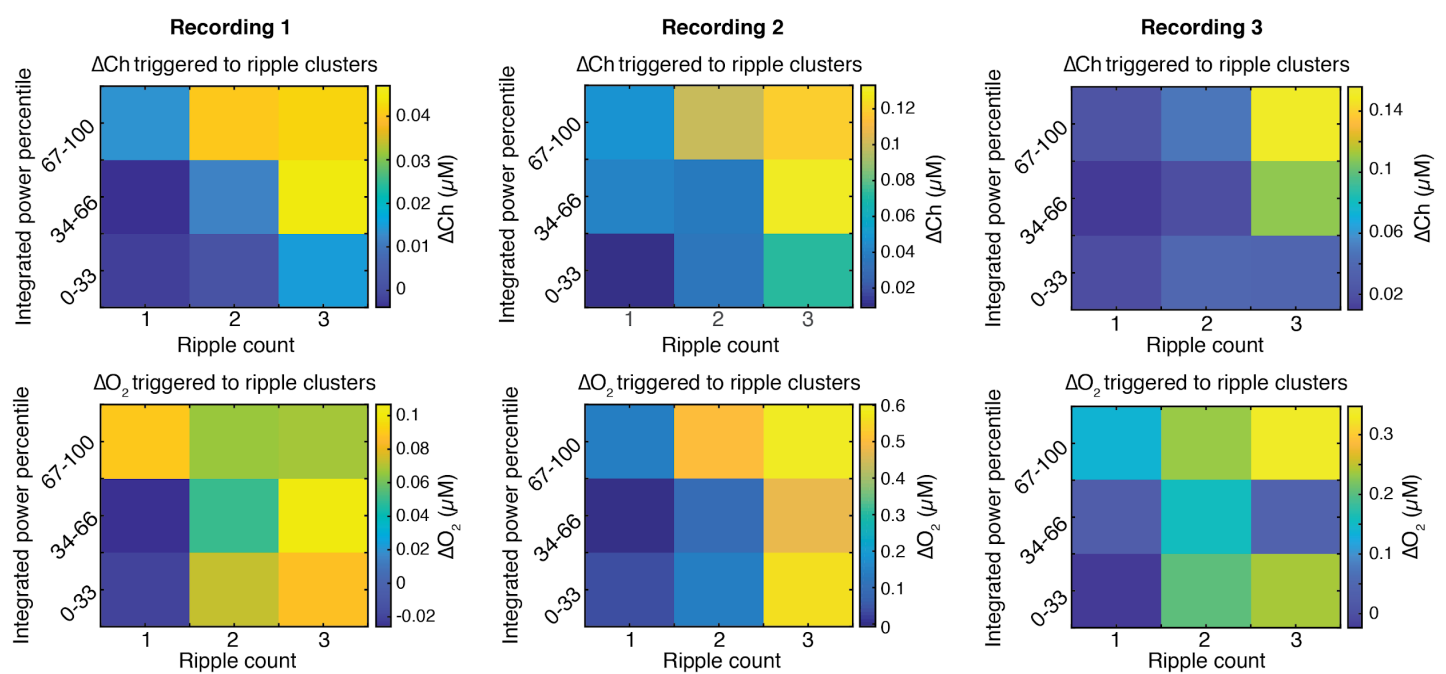

Figure S3. Phasic COA and oxygen responses following SWRs jointly depend on their power and grouping. Amplitude of ChOx activity and $\mathrm{O}_{2}$ transients as a function of SWR count in a $2 \mathrm{~s}$ time window, sorted by different percentile ranges of summed ripple power. The data was collected from three recording sessions. Statistic tests were performed by two-way ANOVA for unbalanced data following ART to account for non-gaussian distributions. In recording session 1, both SWR count and total ripple power significantly affected the amplitude of $\mathrm{ChOx}$ and $\mathrm{O}_{2}(p<0.005$ and $F>5.5$ for both factors in ChOx and $\mathrm{O}_{2}$ data). The same applied for recording $2(p<0.0001$ and $F>12$ for both factors in $\mathrm{ChOx}$ and $\mathrm{O}_{2}$ data). As for recording session 3, the SWR count effect was significant for both sensor signals $(\mathrm{p}<0.05$ and $\mathrm{F}>3.4)$ and the summed ripple power significantly affected $\mathrm{O}_{2}$ $(\mathrm{p}<0.05$ and $\mathrm{F}>4$ ), but was not consistently related to ChOx transients amplitude $(\mathrm{p}=0.07, \mathrm{~F}=2.71)$. 

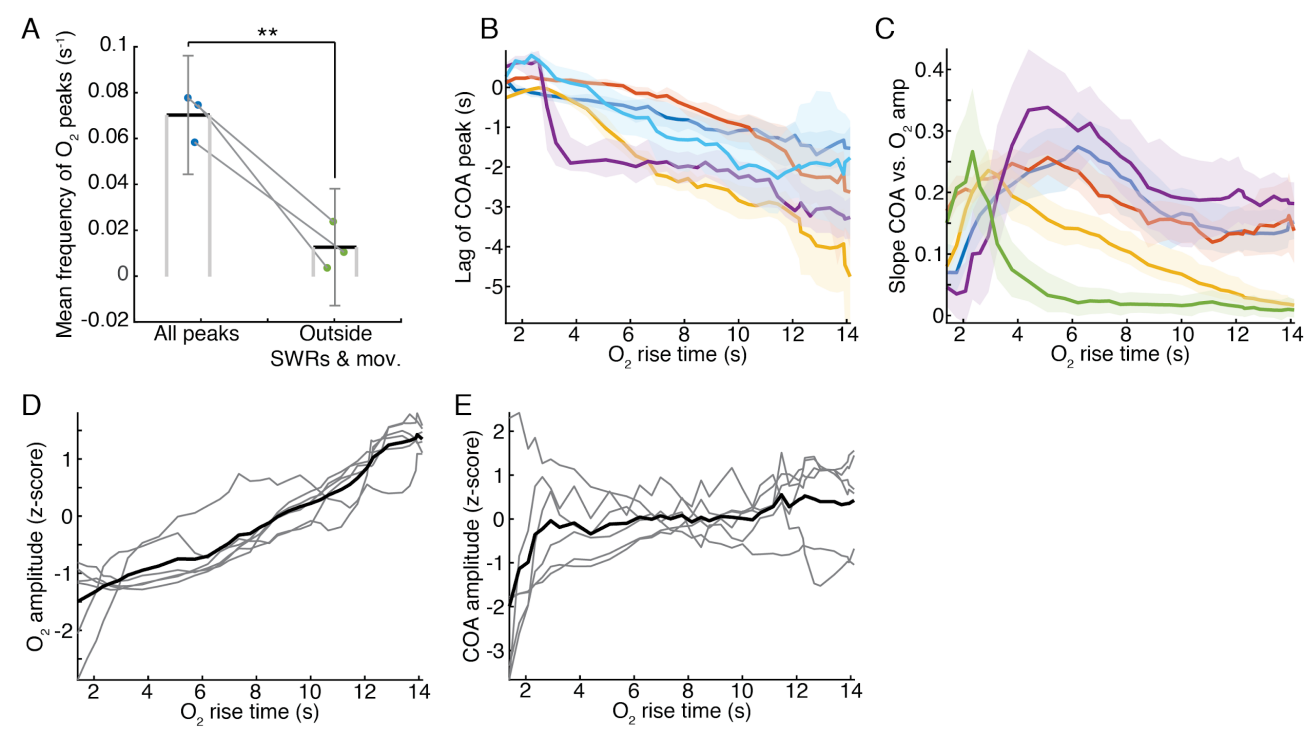

1 Figure S4. COA dynamics associated with $\mathrm{O}_{2}$ transients across all experiments. (A) Mean

2 occurrence rate of $\mathrm{O}_{2}$ peaks during either whole recordings or periods outside SWRs and locomotion

3 bouts (events occurring within $-5 \mathrm{~s}$ to $+1 \mathrm{~s}$ from SWRs or within $-14 \mathrm{~s}$ to $+4 \mathrm{~s}$ from peaks in speed

4 were excluded). The difference between $\mathrm{O}_{2}$ peak rates was significant ( $<<0.01$, paired $t$-test). (B-C)

5 plots display the same statistics as in an example on Figure 5E, but for all recordings (B) Lag of ChOx

6 activity peaks relative to $\mathrm{O}_{2}$ for changes in $\mathrm{O}_{2}$ detected with varying rise time (from whole recordings,

$7 \mathrm{n}=5$ ). Colors represent data from different recording sessions shown as medians \pm CIs. (C) Slope of

8 COA response vs. $\mathrm{O}_{2}$ amplitude for $\mathrm{O}_{2}$ transients detected with a varying rise time. Colors represent 9 data from different recording sessions shown as medians \pm CIs. (D) z-scored amplitude of detected $\mathrm{O}_{2}$ 10 peaks as a function of $\mathrm{O}_{2}$ rise time. Each trace represents medians from each recording. (E) z-scored 11 amplitude of COA transients peaks associated with $\mathrm{O}_{2}$ transients as a function of $\mathrm{O}_{2}$ rise time. Each 12 trace represents medians from each recording. 
bioRxiv preprint doi: https://doi.org/10.1101/2020.08.05.237453; this version posted August 6, 2020. The copyright holder for this preprint (which was not certified by peer review) is the author/funder, who has granted bioRxiv a license to display the preprint in perpetuity. It is made available under aCC-BY 4.0 International license.
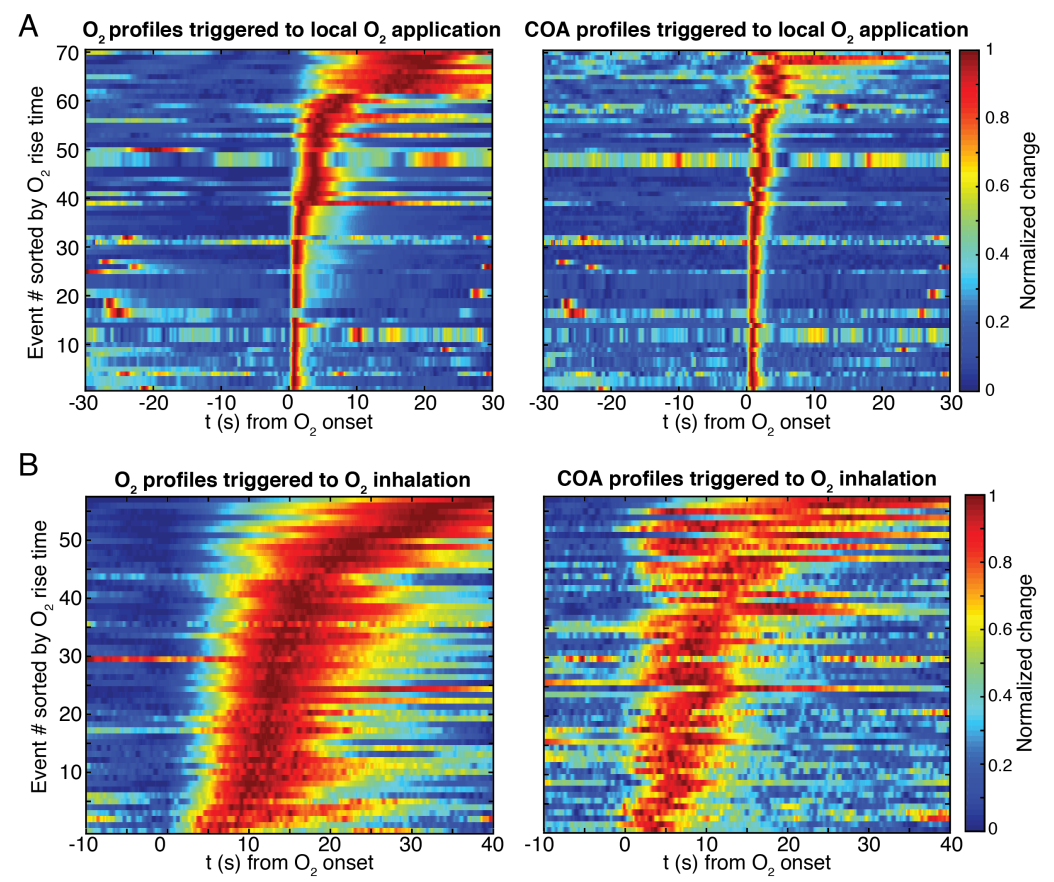

1 Figure S5. Raw sensor responses evoked by exogenous oxygen in vivo. (A) Normalized $\mathrm{O}_{2}$ and 2 COA transients evoked by local $\mathrm{O}_{2}$ application, sorted by $\mathrm{O}_{2}$ rise time. Events were obtained from 3 three recording sessions ( $\mathrm{n}=13-40$ per session). (B) Normalized $\mathrm{O}_{2}$ and COA transients evoked by $\mathrm{O}_{2}$ 4 inhalation, sorted by $\mathrm{O}_{2}$ rise time. Events were obtained from three recording sessions $(\mathrm{n}=8-40$ per 5 session). 

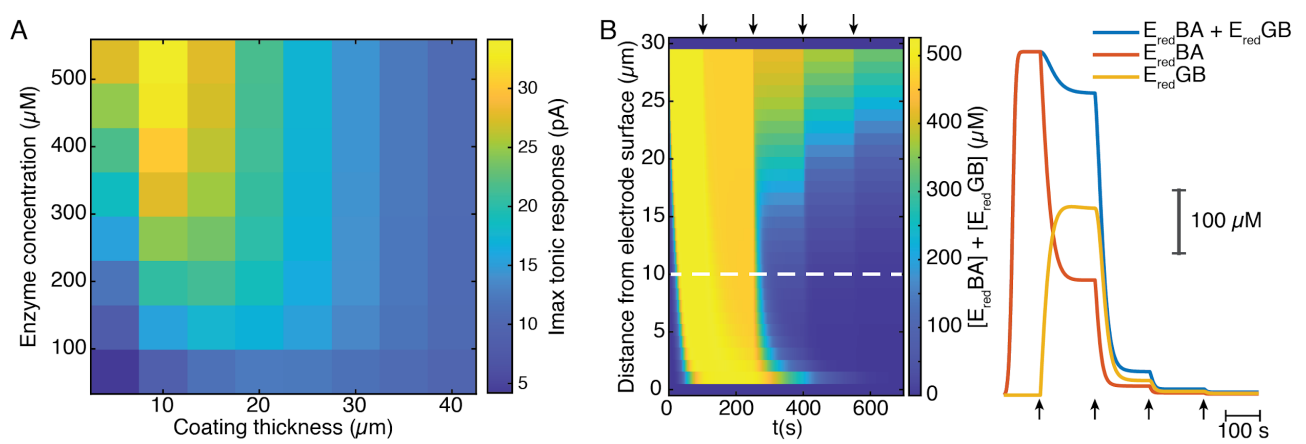

Figure S6. Mathematical simulation of ChOx-biosensor tonic responses and reduced enzymebound intermediate profiles. (A) Maximal cumulative tonic sensor responses as a function of 3 coating thickness and enzyme concentration in the coating. (B) Left shows simulated concentration profile of total reduced enzyme-bound intermediates $\left(\mathrm{E}_{\mathrm{red}} \mathrm{BA}+\mathrm{E}_{\mathrm{red}} \mathrm{GB}\right)$ in the sensor coating as a function of distance from the electrode surface during a simulated calibration of a high enzymeloaded sensor (coating thickness of $30 \mu \mathrm{m}$ and enzyme concentration of $560 \mu \mathrm{M}$ ). Right shows the concentration profile of total and individual enzyme-bound intermediates at $10 \mu \mathrm{m}$ from the electrode surface (dashed line in left panel). Arrows indicate $5 \mu \mathrm{M} \mathrm{O}_{2}$ step increments in solution. 